OPEN ACCESS

Edited by:

Ivan Zanoni,

Harvard Medical School, United States

Reviewed by:

Alessandro Arduini,

Broad Institute, United States

Megan Tierney Baldridge,

Washington University School of

Medicine, United States

Mircea Chiriac,

Universitätsklinikum Erlangen,

Germany

*Correspondence:

Mathias W. Hornef

mhornef@ukaachen.de

these authors have contributed equally to this work.

Specialty section:

This article was submitted to

Molecular Innate Immunity,

a section of the journal

Frontiers in Immunology

Received: 19 June 2017 Accepted: 27 September 2017

Published: 16 October 2017

Citation:

Selvakumar TA, Bhushal S, Kalinke U, Wirth $D$, Hauser $H$, Köster $M$ and Hornef MW (2017) Identification of a Predominantly Interferon- $\lambda$-Induced Transcriptional Profile in Murine Intestinal Epithelial Cells.

Front. Immunol. 8:1302. doi: 10.3389/fimmu.2017.01302

\section{Identification of a Predominantly Interferon- $\lambda$-Induced Transcriptional Profile in Murine Intestinal Epithelial Cells}

\author{
Tharini A. Selvakumar ${ }^{1,2}$, Sudeep Bhushal'2, Ulrich Kalinke ${ }^{3}$, Dagmar Wirth ${ }^{2,4}$, \\ Hansjörg Hauser ${ }^{2}$, Mario Köster ${ }^{2 \dagger}$ and Mathias W. Hornef ${ }^{5 *+}$
}

\begin{abstract}
${ }^{1}$ Hannover Medical School, Institute for Medical Microbiology and Hospital Epidemiology, Hannover, Germany, ${ }^{2}$ Research Group Model Systems for Infection and Immunity, Helmholtz Centre for Infection Research (HZI), Braunschweig, Germany, ${ }^{3}$ Institute for Experimental Infection Research, TWINCORE, Centre for Experimental and Clinical Infection Research, A Joint Venture between the Helmholtz Centre for Infection Research and the Hannover Medical School, Hannover, Germany, ${ }^{4}$ Department of Experimental Hematology, Hannover Medical School, Hannover, Germany, ${ }^{5}$ Institute for Medical Microbiology, RWTH Aachen University Hospital, Aachen, Germany
\end{abstract}

Type I ( $\alpha$ and $\beta$ ) and type III ( $\lambda$ ) interferons (IFNs) induce the expression of a large set of antiviral effector molecules via their respective surface membrane receptors. Whereas most cell types respond to type I IFN, type III IFN preferentially acts on epithelial cells and protects mucosal organs such as the lung and gastrointestinal tract. Despite the engagement of different receptor molecules, the type I and type III IFN-induced signaling cascade and upregulated gene profile is thought to be largely identical. Here, we comparatively analyzed the response of gut epithelial cells to IFN- $\beta$ and IFN- $\lambda_{2}$ and identified a set of genes predominantly induced by IFN- $\lambda_{2}$. We confirm the influence of epithelial cell polarization for enhanced type III receptor expression and demonstrate the induction of predominantly IFN- $\lambda_{2}$-induced genes in the gut epithelium in vivo. Our results suggest that IFN- $\lambda_{2}$ targets the epithelium and induces genes to adjust the antiviral host response to the requirements at mucosal body sites.

Keywords: interferon-lambda, intestinal epithelium, interleukin 28 receptor, transcription, gastrointestinal tract

\section{INTRODUCTION}

The interferon (IFN) family of cytokines acts to confer protection against various pathogens. They are categorized into three different types. Whereas the type II IFN, IFN- $\gamma$, plays a key role in the host response to intracellular bacteria and parasites, members of the type I IFNs- $\alpha$ and $\beta$ and the more recently discovered type III IFNs- $\lambda$ mediate antiviral protection (1-3). Type I and type III IFNs are secreted by a wide range of different cell types upon innate immune stimulation. Differences exist with respect to their transcriptional regulation due to a distinct transcription factor requirement explaining discrepancies in their expression kinetics (4-7). Type I and III IFNs share low amino acid similarity (15-20\%) and bind to structurally very different heterodimeric receptor complexes comprised of the IFN- $\alpha$ receptor (IFNAR) 1 and 2 chain as well as the IFN- $\lambda$ receptor (IFN- $\lambda$ R) 1 and the IL-10 receptor (IL-10R) $\beta$ chain, respectively $(2,3)$. The type I IFN receptor is ubiquitously expressed by all nucleated cells although differences in the expression level and functional sensitivity have been reported $(8,9)$. By contrast, the type III IFN receptor is restricted to epithelial cells 
at mucosal body sites and distinct immune cell subpopulations such as for example polymorphonuclear cells (PMNs) (10-16). Consistently, epithelial cells of the gastrointestinal, respiratory, and reproductive tract were identified as primary targets for type III IFNs in vivo (8-11, 17-21). The type III IFN mediated effect on the epithelium of respiratory and gastrointestinal body surfaces thereby allow an early antiviral response in the absence of the systemic side effects and overt tissue inflammation (22).

Despite differences in their receptor utilization, both type I and type III IFNs engage the Jak/STAT signaling pathway leading to the formation of the IFN-stimulated gene factor (ISGF) 3 complex consisting of STAT1/2 heterodimers together with the interferon regulatory factor 9. ISGF3 translocates to the nucleus and binds to IFN-stimulated response elements in the promoter of so-called IFN-stimulated genes (ISGs) that ultimately generate the antiviral state. In addition to this canonical signaling, IFNAR and IFN- $\lambda \mathrm{R}$ stimulation activates the mitogen-activated protein kinase pathways, i.e., the extracellular signal-regulated kinase (ERK)-1/2, the stress-activated protein kinase/c-Jun N-terminal kinase, and the p38 kinase as well as the phosphatidylinositol 3 -kinase pathway via phosphorylation of Akt $(12,23)$. The functional contribution of these alternative signaling pathways in vivo has remained less well defined.

In accordance with the similarity of the induced signal transduction pathways, the spectrum of genes induced by the two types of IFNs is generally considered to be identical or very similar $(12,20,24-30)$. This finding is consistent with the reported redundant or synergistic action of both types of IFN in vivo $(17,18,20)$ and raises the question on the evolutionary benefit of the two distinct sets of antiviral IFNs and their respective receptors. One possible explanation is a quantitative difference in the cellular response and indeed in vitro studies suggested that the kinetics and magnitude of ISG induction differ between type I and type III IFN stimulation with type I IFN triggering a significantly faster and more potent transcriptional response $(2,3,28,29,31,32)$. However, IFN- $\lambda$ was able to induce ISG expression and efficiently protect from viral infection of the intestinal and respiratory tract in vivo $(8,9,17,19,21,33)$. Another explanation might be previously undetected differences in the gene expression profile that shapes the IFN- $\lambda$ response to better match the specific requirements of the mucosal antiviral host response. For example, IFN- $\lambda$ may contribute to healing following mucosal tissue damage (34).

Comparative analyses of the transcriptional profile induced by type I versus type III IFN have so far been performed on hepatocytes, respiratory epithelial cells, lymphocytes, and total intestinal tissue and failed to identify IFN- $\lambda$-specific targets $(12,20,24-30)$. The most discriminatory response between type I and type III IFN has, however, so far been reported at the intestinal epithelium which represents the entry port for many pathogenic viruses (9). We therefore took advantage of the recently established Mx2luciferase transgenic gut epithelial IEC10 cells that exhibit many typical features of the intestinal epithelium and respond robustly to both type I and type III IFN (32). Comparative transcriptomic profiling of polarized intestinal epithelial cells identified a predominantly IFN- $\lambda_{2}$-induced set of genes. Selected target genes were confirmed in vivo by an analysis of intestinal epithelial cells prepared from IFN $-\lambda_{2}$ treated IFNAR ${ }^{-/-}$mice, and the critical involvement of enterocyte polarization for IL-28R expression was demonstrated.

\section{MATERIALS AND METHODS}

\section{Ethics Statement}

All animal experiments were performed in compliance with the German animal protection law (TierSchG) and approved by the local animal welfare committee Niedersächsisches Landesamt für Verbraucherschutz und Lebensmittelsicherheit Oldenburg, Germany. Mice were housed under specific pathogen-free conditions and handled in accordance with regulations defined by FELASA and the national animal welfare body GV-SOLAS. ${ }^{1}$

\section{Animals}

B6.A2G-Mx1-IFNAR1 ${ }^{-/}$mice lacking functional type I IFN receptors (IFNAR1 ${ }^{-1-}$ ), B6.A2G-Mx1-IL28 $\alpha^{-/-}$mice carrying intact $M x 1$ alleles, and lacking a functional type III IFN receptor (IL28R $\alpha^{-1-}$ ) were bred at the Central Mouse Facility of the Helmholtz Centre for Infection Research, Braunschweig and described elsewhere (17).

\section{In Vitro Cell Culture}

The intestinal epithelial cell line (IEC) Mx2Luc was generated from a transgenic mouse containing the firefly luciferase gene under control of the $\mathrm{Mx} 2$ promoter region as described earlier (32). IECs were cultured at $37^{\circ} \mathrm{C}, 5 \% \mathrm{CO}_{2}, 95 \% \mathrm{RH}$ and maintained in IEC medium (32). For cell culture under non-polarized conditions (2D), IECs were seeded in 12-well or 24-well plates at a seeding density of $2 \times 10^{5}$ or $2 \times 10^{4}$ cells, respectively, and grown to confluence. For cell culture under polarized conditions (3D), IECs were seeded at a cell density of $2 \times 10^{5}$ cells $/ \mathrm{mL}$ on $0.4 \mu \mathrm{m}$ pore size transwell cell-culture inserts (Costar). Cells were allowed to grow for 21 days to attain polarization. The cell-culture medium was changed every 3 days, and transepithelial resistance was measured (EVOM, World Precision instruments) to determine the establishment of epithelial barrier integrity. IECs were stimulated with $500 \mathrm{U} / \mathrm{mL}$ IFN- $\beta$ (19) or $20 \mathrm{ng} / \mathrm{mL}$ IFN- $\lambda_{2}$ (Peprotech) in cell-culture medium.

\section{Isolation and Culture of Primary Cells}

For isolation of primary intestinal epithelial cells, small intestinal tissue was harvested and cut into $3-4 \mathrm{~cm}$ pieces. The tissueassociated fat tissue was removed using forceps, and the intestine was turned inside out. The inverted tissue was mounted on an inoculation loop, incubated for $10 \mathrm{~min}$ in $30 \mathrm{mM} \mathrm{EDTA}$ at $37^{\circ} \mathrm{C}$ and subjected to centrifugal force with a biovortexer (Sigma) using 10-12 pulses with 1-2 s duration. Epithelial cell fragments were separated from contaminating lymphoid and myeloid single cells by threefold sedimentation at $1 \times g$ for $20 \mathrm{~min}$ at $4^{\circ} \mathrm{C}$ leading to a final purity of E-cadherin positive epithelial cells of 85-90\% (35). Bone marrow-derived dendritic cells (BMDCs) were obtained from female C57BL/6 WT mice by flushing the

${ }^{1}$ www.gv-solas.de 
bone marrow from the cavities of femurs and tibiae. Erythrocytes were depleted with ACK lysis buffer (Thermo Fisher Scientific), and the cells were plated in 12-well cell-culture plates at a seeding density of $1 \times 10^{6}$ cells $/ \mathrm{mL}$ in the presence of Flt3L at $100 \mathrm{ng} / \mathrm{mL}$ (PeproTech, Rocky Hill, NJ, USA) in complete medium (RPMI supplemented with $10 \%$ heat-inactivated fetal bovine serum, $1 \%$ penicillin/streptomycin, $1 \%$ glutamine, and $50 \mu \mathrm{g} / \mathrm{mL}$ gentamicin). Cultures were replenished with fresh medium every other day and stimulated at day 7. Primary alveolar epithelial cells were isolated using a modified protocol previously established (36). Briefly, the trachea of the anesthetized and exsanguinated mice was exposed and the lungs were perfused with 10-20 mL sterile PBS buffer until they were free of blood. $1 \mathrm{~mL}$ of dispase (BD Biosciences) was flushed into the lungs via the trachea. The lungs were removed and placed in a cell-culture dish containing an additional $1 \mathrm{~mL}$ of dispase and were cut into small pieces. They were then transferred to a $15 \mathrm{~mL}$ Falcon and incubated for $45 \mathrm{~min}$ at $37^{\circ} \mathrm{C}$ with gentle shaking. The crude cell suspension was passed through a sterile $70 \mu \mathrm{m}$ strainer, and the resulting cell suspension was centrifuged at 1,500 rpm for $5 \mathrm{~min}$. The pellet obtained was incubated in $5 \mathrm{~mL}$ of ACK buffer for erythrocyte depletion for $5 \mathrm{~min}$ and subsequently subjected to another round of centrifugation at $1,500 \mathrm{rpm}$ for $5 \mathrm{~min}$. Cells were stained with Epcam-PE (eBioscience) and magnetically sorted (MACS anti-PE Microbeads, Miltenyi Biotec $\mathrm{GmbH}$ ) to obtain a highly enriched population of epithelial cells. Cells were plated in 12 -well cell-culture plates at a seeding density of $1 \times 10^{6}$ cells $/ \mathrm{mL}$ and stimulated after 5 days in culture.

\section{Gene Expression Analysis}

RNA from cell-culture experiments was isolated using the RNeasy mini kit (Qiagen) based on silica membrane containing centrifugation columns following the manufacturer's instructions. Total RNA from primary epithelial cells was isolated by guanidinium thiocyanate-phenol-chloroform extraction using Trizol LS reagent (Life Technologies) according to the manufacturer's instructions. 1-2 $\mu \mathrm{g}$ RNA was reversely transcribed into cDNA using the RevertAid RT Kit (Thermo Fisher Scientific). Newly synthesized cDNA was subjected to quantitative real-time PCR analysis in a total volume of $20 \mu \mathrm{l}$, using the SYBR Green PCR Kit (BioRad) in combination with a LightCycler 480 II (Roche). The expression level of the house-keeping gene $\beta$-actin in IEC10 cells was unaffected by IFN- $\beta$ or IFN- $\lambda_{2}$ stimulation (Figure S2A in Supplementary Material). Changes in gene expression were calculated relative to the endogenous control $\beta$-actin using the formula $2^{-\Delta \mathrm{Ct}}$. Experiments demonstrated no influence of IFN stimulation on the $\beta$-actin mRNA expression level (data not shown). The values obtained for individual genes after stimulation with IFN- $\beta$ or IFN- $\lambda_{2}$ were subsequently divided by the mean values found in untreated cells (PBS). Gene expression values are presented as fold induction over the unstimulated control. Statistical analysis was performed using a (non-parametric) one-way analysis of variance (ANOVA) test with Tukey's post test, and the data are presented as mean \pm SEM. The values obtained for in vivo gene expression were normalized to the endogenous control $\beta$-actin, statistically analyzed by the Mann-Whitney $U$ test and are represented as mean \pm SEM from two to three independent experiments. Murine PCR primers for $\beta$-actin (forward primer, $5^{\prime}$-TGG AAT CCT GTG GCA TCC ATG AAA C-3' and reverse primer, 5'-TAA AAC GCA GCT CAG TAA CAG TCC G-3'), Usp18 (forward primer, 5' -CAT CCT CCA GGG TTT TCA GA-3' and reverse primer, $5^{\prime}$-AAG GAC CAG ATC ACG GAC AC-3'), Ifi44 (forward primer, $5^{\prime}$-AAC TGA CTG CTC GCA ATA ATG T-3' and reverse primer, $5^{\prime}$-GTA ACA CAG CAA TGC CTC TTG T-3'), Ifit1 (forward primer, 5' -TGT TGA AGC AGA AGC ACA CA-3' and reverse primer, 5'-TCT ACG CGA TGT TTC CTA CG-3'), Mmp7 (forward primer, 5'-TAG GCG GAG ATG CTC ACT TT-3' and reverse primer, 5' ${ }^{\prime}$ TTC TGA ATG CCT GCA ATG TC-3'), Serpinb1a (forward primer, 5'-GCT GCT ACA GGA GGC ATT GC-3' and reverse primer, 5'-CGG ATG GTC CAC TGT GAA TTC-3'), Csprs (forward primer, 5'-AGA GAG GCA GAG GGA CTG AG-3' and reverse primer, 5'-GGC TTG GCT CCT GAA CAC TT-3'), IL28R (forward primer, $5^{\prime}$-CCC TGT TTC CTG ACA CTC CC-3' and reverse primer, $5^{\prime}$-TCA GAA AAG TCC AGT GCC CG-3'), IL10R (forward primer, 5'-TCT CTT CCA CAG CAC C-3' and reverse primer, 5'-GAA CAC CTC GCC CTC C-3'), Ifnar 1 (forward primer, 5' -CTG GTC TGT GAG CTG TAC TT-3' and reverse primer, 5'-TCC CCG CAG TAT TGA TGA GT-3'), Ifnar2 (forward primer, 5'-CTA TCG TAA TGC TGA AAC GG-3' and reverse primer, 5'-CGT AAT TCC ACA GTC TCT TCT-3').

\section{Microarray Analysis}

Microarray analysis was performed in triplicates on 3D-grown unstimulated or IFN-stimulated IECs. RNA was extracted using the RNeasy Mini Kit (Qiagen) according to the manufacturer's protocol. Microarray data used or referred to in this publication were generated by the Research Core Unit Transcriptomics of Hannover Medical School. Synthesis of Cy3-labeled cRNA was performed with the Quick Amp Labeling kit, one color (Agilent Technologies) according to the manufacturer's recommendations. cRNA fragmentation, hybridization, and washing steps were also carried out exactly as recommended: "One-Color Microarray-Based Gene Expression Analysis Protocol V5.7." Microarray analysis was performed using Whole Mouse Genome Oligo Microarray GPL11202 (Agilent Technologies). Slides were scanned on the Agilent Micro Array Scanner G2565CA (pixel resolution $5 \mu \mathrm{m}$, bit depth 20). Data extraction was performed with the "Feature Extraction Software V10.7.3.1" by using the recommended default extraction protocol file: “GE1_107_Sep09.xml." Measurements of on-chip replicates were averaged using the geometric mean of processed intensity values of the green channel, "gProcessedSignal" (gPS) to retrieve one resulting value per unique non-control probe. Single features were excluded from averaging, if they (i) were manually flagged, (ii) were identified as outliers by the feature extraction software, (iii) lie outside the interval of " $1.42 \times$ interquartile range" regarding the normalized gPS distribution of the respective on-chip replicate population, or, (iv) showed a coefficient of variation of pixel intensities per Feature that exceeded 0.5. Averaged gPS values were normalized by global linear scaling. For this approach, all gPS values of one sample were multiplied by an array-specific scaling factor. This factor was calculated by dividing a "reference 75th Percentile value" (set as 1,500 for 
the whole series) by the 75th Percentile value of the particular Microarray to be scaled ("Array I" in the formula shown below). Accordingly, normalized gPS values for all samples (microarray data sets) were calculated by the following formula: normalized gPSArray i $=$ gPSArray i $\times(1,500 / 75$ th PercentileArray i). A lower intensity threshold (surrogate value) was defined based on intensity distribution of negative control features. This value was fixed at 15 normalized gPS units. All measurements that fell below this intensity cutoff were substituted by the respective surrogate value of 15 . The hierarchical clustering heatmap was generated using Qlucore Omics explorer (multigroup analysis: $p$-value $=0.003 ; q$-value $=0.05$; two-group analysis: $p$-value $=0.001 ; q$-value $=0.05$, fold change cutoff $=2)$. The group definitions for the IFN-induced genes (Figure 1C) were as follows: "predominantly IFN- $\lambda_{2}$-induced gene": fold increase by IFN- $\lambda_{2}$ over control/fold increase by IFN- $\beta$ over control $>4.5$ and fold increase by IFN- $\beta$ over control $<2$; "strong IFN$\lambda_{2}$-induced gene": fold increase by IFN- $\lambda_{2}$ over control/fold increase by IFN- $\beta$ over control $>2$ and fold increase by IFN- $\beta$ over control >2: "Classical ISGs" were defined by their designation in the literature. Cluster of orthologous group analysis was performed using the PANTHER software ${ }^{2}$ Expression array data are available through GEO Series accession number GSE91382.

\section{Statistical Analysis}

The one-way ANOVA test (with Tukey's posttest) and the Mann-Whitney $U$ test were employed for statistical analysis of quantitative RT-PCR results. The GraphPad Prism Software 7.00 was used for statistical evaluation.

\section{RESULTS}

\section{IFN- $\lambda_{2}$ Induces a Unique Transcriptional Profile in Polarized IECs}

The recently described intestinal epithelial IEC10 cells exhibit many properties of the natural epithelium. They respond to both type I and type III IFNs and generate a robust antiviral state making them an ideal model to study IFN-induced gene expression (32). IEC10 cells were grown to confluency on transwell cell-culture inserts and left untreated or stimulated with IFN- $\beta(500 \mathrm{U} / \mathrm{mL})$ or IFN- $\lambda_{2}(20 \mathrm{ng} / \mathrm{mL})$ for $9 \mathrm{~h}$. The selected IFN concentrations induced a submaximal stimulatory response (approximately $90 \%$ of the maximal $\mathrm{Mx} 2$ gene induction) in IEC10 cells for both cytokines as recently reported (32). Similar IFN concentrations have also been used in other comparative studies $(9,12,20,24-30)$. The stimulation time $(9 \mathrm{~h})$ was selected based on the kinetic of ISG (Mx2) induction following IFN- $\beta$ and/or IFN- $\lambda_{2}$ exposure and allowed a stable gene induction for both cytokines (Figure S1B in Supplementary Material). Total RNA was isolated and subjected to transcriptome analysis. Normalization and multigroup analysis (ANOVA) revealed a total of 2,465 significantly differentially regulated genes $(q$-value $=0.05, p$-value $=0.003)$. Figure 1A illustrates the genes significantly induced by IFN- $\beta$ and/or IFN- $\lambda$. In a

${ }^{2}$ http://www.pantherdb.org/. second approach, we subjected the genes through a two-group analysis (filtering criteria: $q$-value $=0.0499, p$-value $=0.001$, fold change cutoff $=2$ ) and observed that 349 genes were highly expressed after stimulation with IFN- $\lambda_{2}$ but not IFN- $\beta$ (Figure S2A in Supplementary Material). In a third approach, the top 100 (fold over control) IFN- $\lambda_{2}$-induced genes were selected (Table 1) and examined in a correlation analysis for their induction by IFN- $\beta$ versus IFN- $\lambda_{2}$ revealing a majority of classical ISGs including the prototypical antiviral genes Ifi44 and Ifit1 as presented in Figures 1B,C (left panel). Among these genes, also a group of genes predominantly induced by IFN- $\lambda_{2}$ and a group of genes strongly induced by IFN- $\lambda_{2}$ was identified (Figure 1B labeled in red and blue, respectively, and Figure 1C middle and right panel). These genes were found to be mainly involved in cellular and metabolic processes and cellular responses to stimuli such as innate host defense, substrate transport and ion homeostasis (Figures S2B,C in Supplementary Material). Two predominantly IFN- $\lambda_{2}$-induced genes, Mmp7 and Serpinb1a, one strongly IFN- $\lambda_{2}$-induced gene, Csprs, as well as the classical antiviral ISGs Usp18, Ifi44, and Ifit1 were randomly selected and their transcriptional profile upon stimulation with type I or type III IFN for $9 \mathrm{~h}$ was confirmed by quantitative RT-PCR (Figures 1D,E). IFN- $\beta$ was unable to induce expression of the predominantly IFN- $\lambda_{2}$-induced genes $M m p 7$ and Serpinb $1 a$ also at other time points (Figure 1F; Figure S3 in Supplementary Material).

\section{Expression of Predominantly IFN- $\lambda_{2}-$ Induced Genes Requires Epithelial Cell Polarization}

Apical-basolateral polarization represents a key feature of intestinal epithelial cells and is intimately linked to their physiological function such as barrier formation and nutrient absorption. To investigate the influence of cell polarization on IFN-induced gene expression, IEC10 cells were grown on conventional flat bottom culture dishes (2D) and stimulated with IFN- $\beta(500 \mathrm{U} / \mathrm{mL})$ or IFN- $\lambda_{2}(20 \mathrm{ng} / \mathrm{mL})$ for $9 \mathrm{~h}$. RT-PCR confirmed the ability of IFN- $\beta$ and IFN- $\lambda_{2}$ to enhance the expression of the prototypical ISGs Usp18, Ifi44, and Ifit1 (Figure 2A). The Usp18, Ifi44, and Ifit1 mRNA levels reached in response to IFN- $\lambda_{2}$ were less pronounced as compared with under polarized conditions. Due to the lower gene expression levels of unstimulated controls, however, the fold induction was unchanged or even increased (Figure 1D). Notably, IFN- $\lambda_{2}$ failed to enhance the expression of Mmp7, Serpinb1a, and Csprs under non-polarizing conditions (Figure 2B). Epithelial polarization might therefore critically influence the qualitative IFN- $\lambda$ response. In an attempt to understand the underlying mechanism, IEC10 cells grown on flat bottom culture dishes (2D) or transwell inserts (3D) were comparatively examined for the expression levels of the IFN receptor molecules under homeostatic conditions. Epithelial cells displayed significantly increased levels of the IL-28R $\alpha$ and IL-10R $\beta$ chain expression when they attained polarization as compared with their non-polarized state (Figure 2C) whereas no influence of polarization was noted for the type I IFN receptor IFNAR1 and 2 (Figure 2D) consistent with a recent report (37). 
A

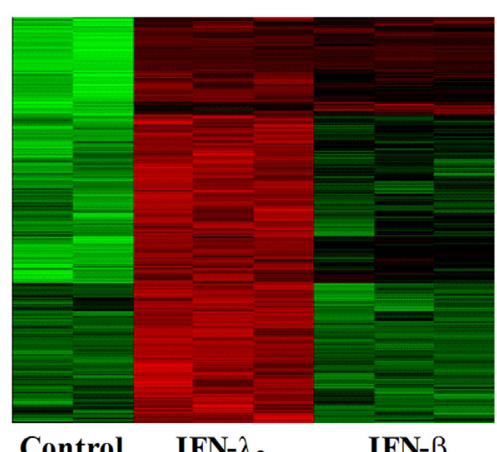

Control IFN- $\lambda_{2} \quad$ IFN- $\beta$

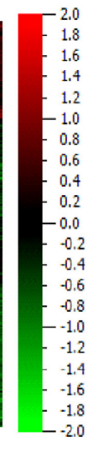

Predominantly IFN- $\lambda_{2}$ induced genes

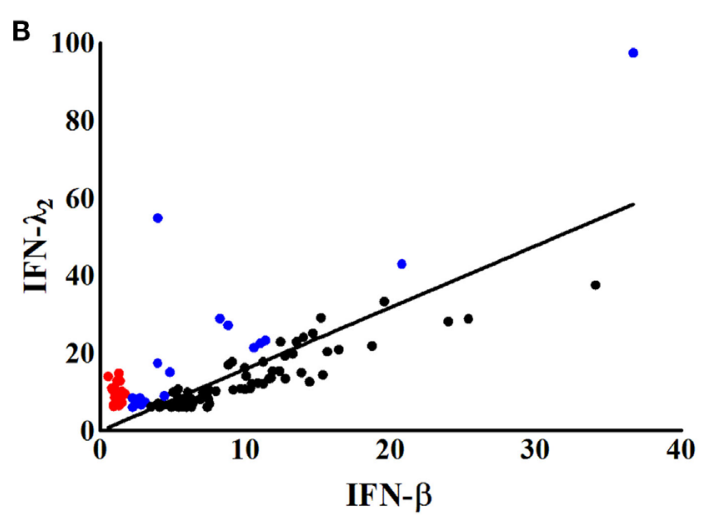

C

Classical ISGs

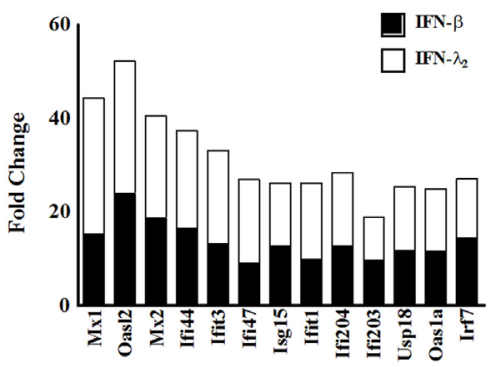

D

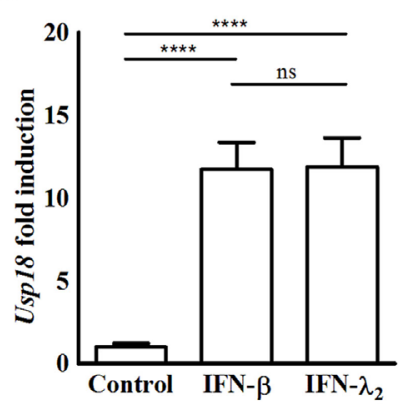

E

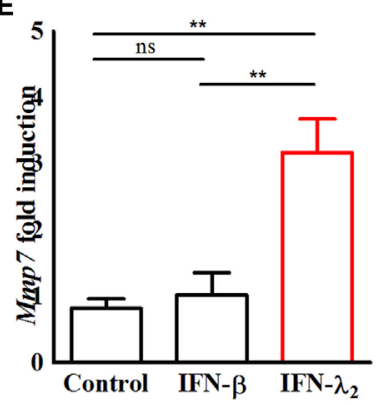

$\mathbf{F}$

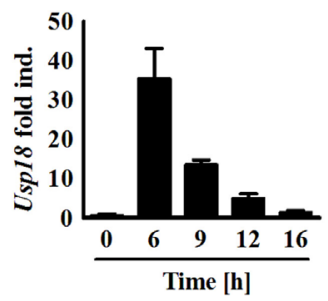

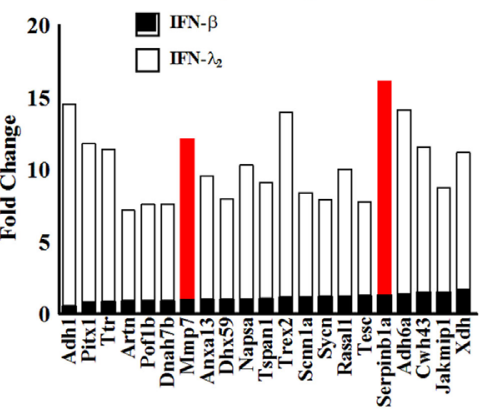
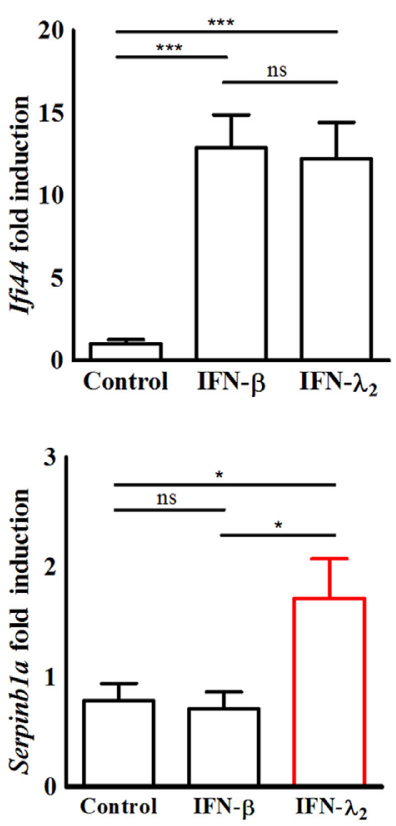

Strongly IFN- $\lambda_{2}$ inducedgenes

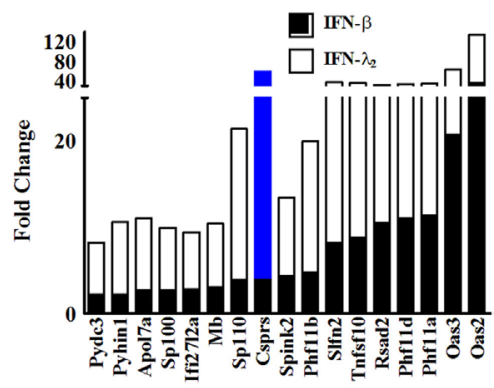

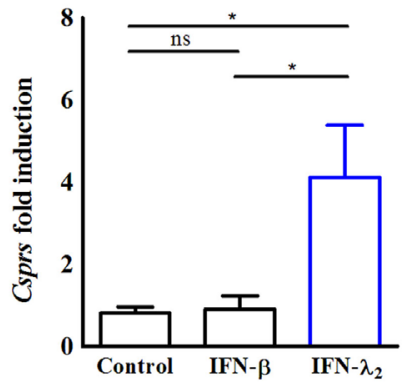
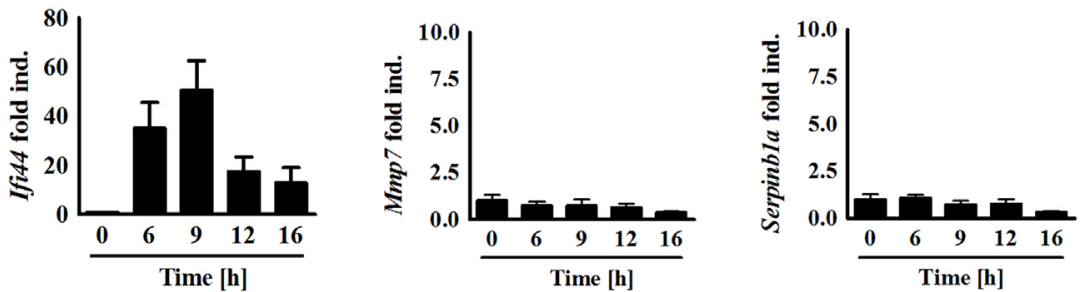


\section{FIGURE 1 | Continued}

Identification and confirmation of a predominantly interferon (IFN)- $\lambda_{2}$-induced gene expression profile. (A) Heatmap of the genes expressed by IEC10 cells cultured on transwell filter inserts and left untreated (PBS) or exposed to IFN- $\lambda_{2}(20 \mathrm{ng} / \mathrm{mL})$ or IFN- $\beta(500 \mathrm{U} / \mathrm{mL})$ for $9 \mathrm{~h}$. Data were obtained using a global gene expression array. Multigroup comparison was carried out at $p=0.003, q=0.05$. (B) Selective analysis of the top 100 genes induced by IFN- $\lambda_{2}$ as identified by fold increase over unstimulated control. Correlation graph showing the fold change of these 100 genes in respect to their induction by IFN- $\lambda_{2}$ (20 ng/mL) versus IFN- $\beta(500 \mathrm{U} / \mathrm{mL}$ ) $9 \mathrm{~h}$ after stimulation. Red labeled dots illustrate a subgroup of genes that is predominantly induced by IFN- $\lambda 2$; blue dots illustrate a subgroup of genes strongly induced by IFN- $\lambda 2$ (for definition see Section "Materials and Methods"). (C) Graphical representation showing the fold change analysis of different gene subgroups ["classical antiviral IFN-stimulated genes (ISGs)," "predominantly IFN- $\lambda_{2}$-induced genes," "strongly IFN- $\lambda_{2}$-induced genes"]. (D,E) Quantitative RT-PCR for (D) the prototypical ISGs Usp18, Ifi44, and Ifit1, (E) the predominantly IFN- $\lambda_{2}$-induced ISGs Mmp7, Serpinb1a, and the strongly IFN- $\lambda_{2}$-induced gene Csprs performed on total RNA isolated from IEC10 cells grown on transwell inserts and stimulated for $9 \mathrm{~h}$ with IFN- $\lambda_{2}(20 \mathrm{ng} / \mathrm{mL})$ or IFN- $\beta$ ( $500 \mathrm{U} / \mathrm{mL}$ ). The results are represented as mean \pm SEM values from two to three independent experiments and are normalized to the values obtained for the housekeeping gene $\beta$-actin. Statistical significance was calculated using the one-way analysis of variance (with Tukey's posttest). (F) Quantitative RT-PCR for the prototypical ISGs Usp18 and Ifi44 as well as the predominantly IFN- $\lambda_{2}$-induced ISGs Mmp7 and Serpinb1a performed on total RNA isolated from IEC10 cells grown on transwell filter inserts and stimulated with IFN- $\beta(500 \mathrm{U} / \mathrm{mL})$ for the indicated time period. The results represent the mean \pm SEM values from two to three independent experiments and are normalized to the values obtained for the housekeeping gene $\beta$-actin.

TABLE 1 | Top 100 genes induced by IFN- $\lambda 2$.

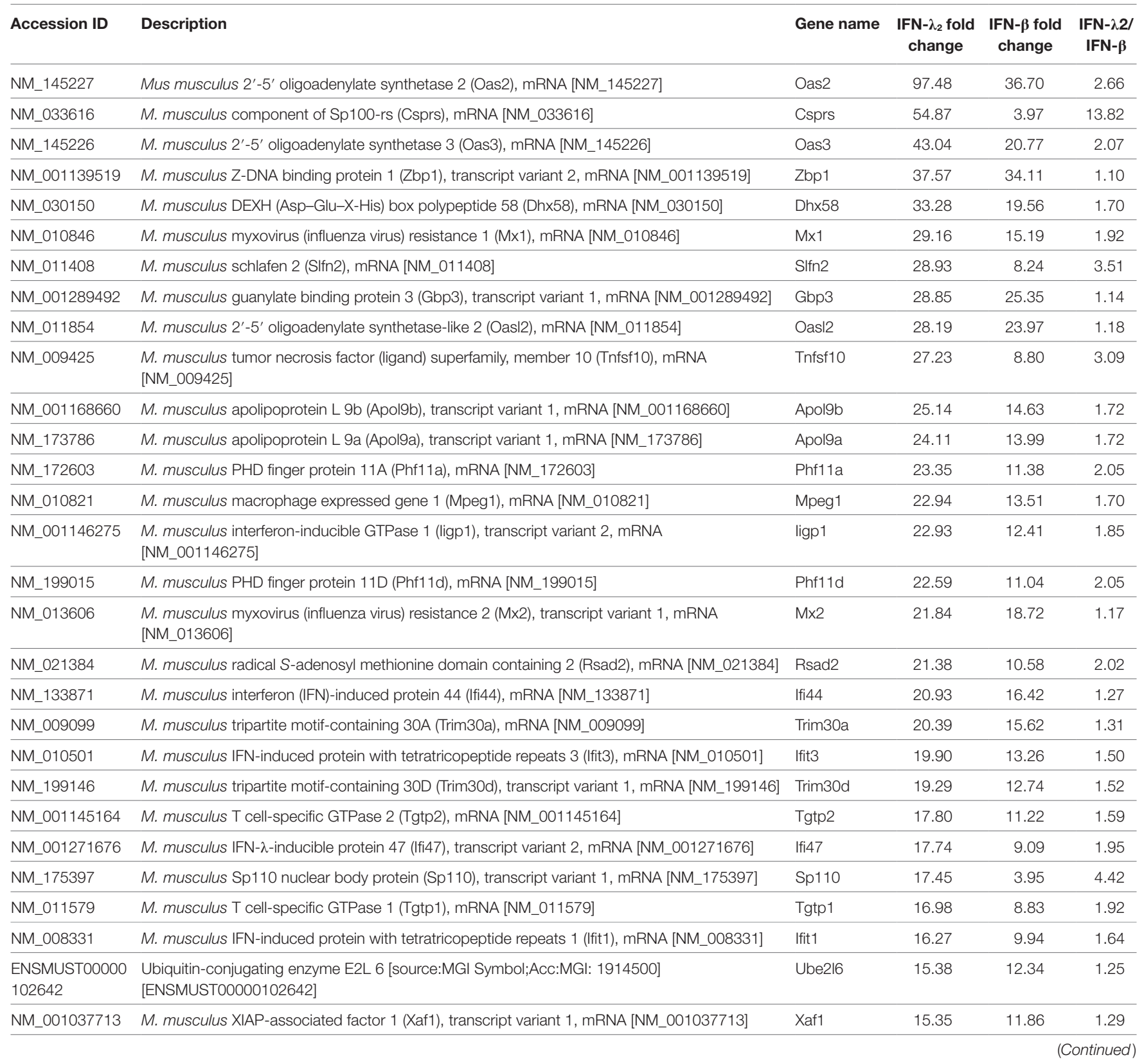


TABLE 1 | Continued

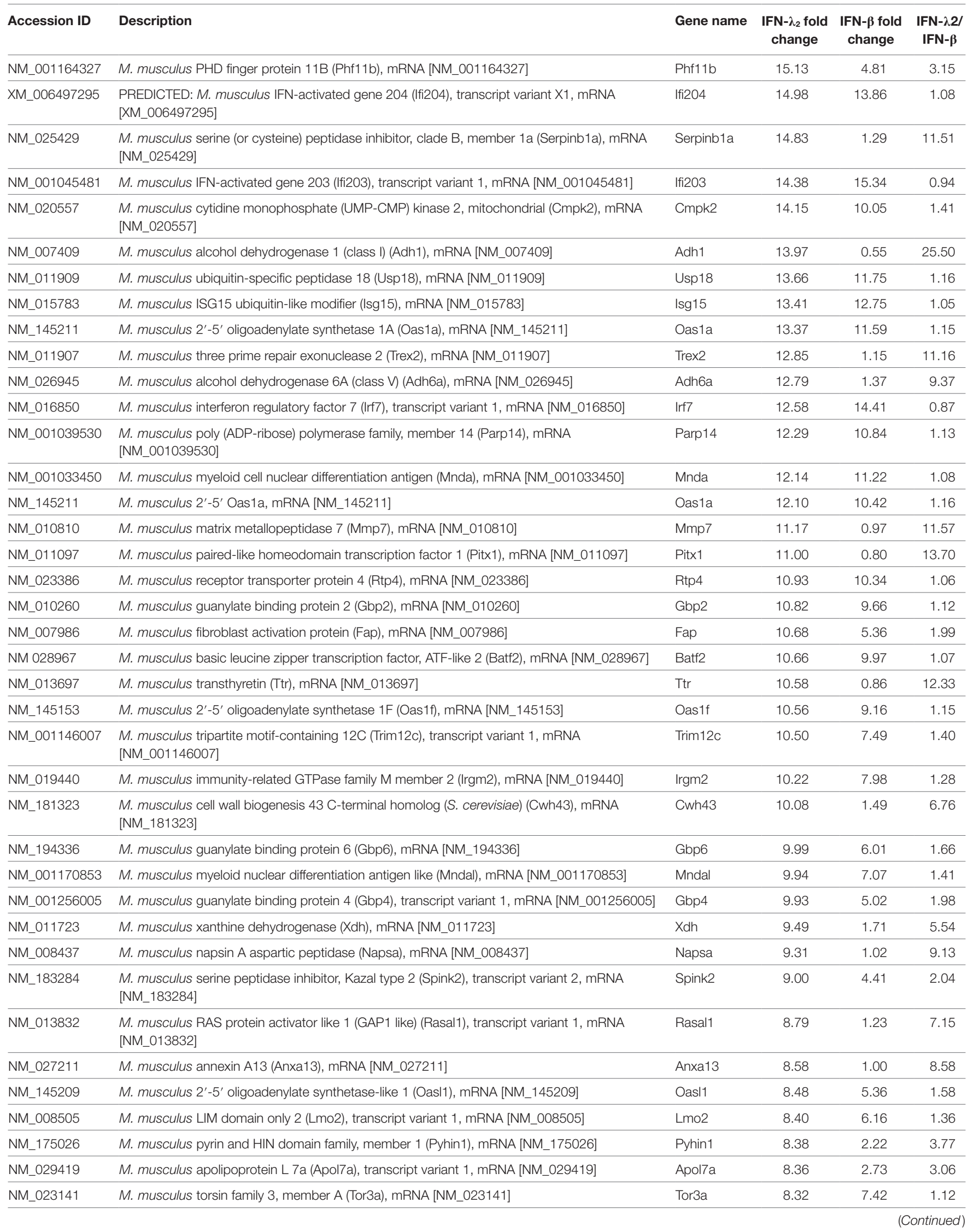


TABLE 1 | Continued

\begin{tabular}{|c|c|c|c|c|c|}
\hline Accession ID & Description & Gene name & $\begin{array}{l}\text { IFN- } \lambda_{2} \text { fold } \\
\text { change }\end{array}$ & $\begin{array}{l}\text { IFN- } \beta \text { fold } \\
\text { change }\end{array}$ & $\begin{array}{l}\text { IFN- } \lambda 2 / \\
\text { IFN- } \beta\end{array}$ \\
\hline NM_008326 & M. musculus immunity-related GTPase family M member 1 (Irgm1), mRNA [NM_008326] & $\operatorname{lrgm1}$ & 8.16 & 6.84 & 1.19 \\
\hline NM_011852 & M. musculus 2'-5' oligoadenylate synthetase 1G (Oas1g), mRNA [NM_011852] & Oas1g & 8.11 & 5.56 & 1.46 \\
\hline NM_145545 & M. musculus guanylate binding protein 7 (Gbp7), transcript variant 1, mRNA [NM_145545] & Gbp7 & 8.11 & 6.28 & 1.29 \\
\hline NM_010708 & $\begin{array}{l}\text { M. musculus lectin, galactose binding, soluble } 9 \text { (Lgals9), transcript variant 1, mRNA } \\
\text { [NM_010708] }\end{array}$ & Lgals9 & 8.06 & 6.89 & 1.17 \\
\hline NM_133681 & M. musculus tetraspanin 1 (Tspan1), mRNA [NM_133681] & Tspan1 & 8.05 & 1.07 & 7.56 \\
\hline NM_010426 & M. musculus forkhead box F1 (Foxf1), mRNA [NM_010426] & Foxf1 & 7.67 & 6.22 & 1.23 \\
\hline NM_013593 & M. musculus myoglobin (Mb), transcript variant 2, mRNA [NM_013593] & $\mathrm{Mb}$ & 7.33 & 3.09 & 2.37 \\
\hline NM_178394 & M. musculus janus kinase and microtubule interacting protein 1 (Jakmip1), mRNA [NM_178394] & Jakmip1 & 7.24 & 1.49 & 4.85 \\
\hline NM_013673 & M. musculus nuclear antigen Sp100 (Sp100), mRNA [NM_013673] & Sp100 & 7.23 & 2.74 & 2.64 \\
\hline NM_011324 & M. musculus sodium channel, non-voltage-gated 1 alpha (Scnn1a), mRNA [NM_011324] & Scnn1a & 7.22 & 1.18 & 6.10 \\
\hline NM_145226 & M. musculus 2'-5' oligoadenylate synthetase 3 (Oas4), mRNA [NM_145226] & Oas4 & 7.04 & 3.98 & 1.77 \\
\hline NM_001139519 & M. musculus Z-DNA binding protein 2 (Zbp2), transcript variant 2, mRNA [NM_001139519] & Zbp2 & 6.99 & 6.35 & 1.10 \\
\hline NM_030150 & M. musculus DEXH (Asp-Glu-X-His) box polypeptide 58 (Dhx58), mRNA [NM_030150] & Dhx59 & 6.98 & 1.01 & 6.93 \\
\hline NM_025378 & M. musculus IFN-induced transmembrane protein 3 (Ifitm3), mRNA [NM_025378] & Ifitm3 & 6.94 & 7.55 & 0.92 \\
\hline NM_197944 & M. musculus hematopoietic SH2 domain containing (Hsh2d), mRNA [NM_197944] & Hsh2d & 6.72 & 4.40 & 1.53 \\
\hline NM_001160386 & M. musculus dynein, axonemal, heavy chain 7B (Dnah7b), mRNA [NM_001160386] & Dnah7b & 6.72 & 0.92 & 7.29 \\
\hline NM_026716 & M. musculus syncollin (Sycn), mRNA [NM_026716] & Sycn & 6.71 & 1.21 & 5.53 \\
\hline NM_023835 & M. musculus tripartite motif-containing 12A (Trim12a), mRNA [NM_023835] & Trim12a & 6.70 & 5.83 & 1.15 \\
\hline NM_181579 & M. musculus premature ovarian failure 1B (Pof1b), mRNA [NM_181579] & Pof1b & 6.68 & 0.92 & 7.26 \\
\hline NM_029803 & $\begin{array}{l}\text { M. musculus IFN, alpha-inducible protein 27-like 2A (Ifi27l2a), transcript variant 1, mRNA } \\
\text { [NM_029803] }\end{array}$ & Ifi27|2a & 6.65 & 2.82 & 2.36 \\
\hline NM_021344 & M. musculus tescalcin (Tesc), mRNA [NM_021344] & Tesc & 6.51 & 1.28 & 5.09 \\
\hline NM_181728 & M. musculus ADP-ribosyltransferase 3 (Art3), mRNA [NM_181728] & Art3 & 6.45 & 5.17 & 1.25 \\
\hline NM_001284192 & M. musculus artemin (Artn), transcript variant 2, mRNA [NM_001284192] & Artn & 6.29 & 0.91 & 6.91 \\
\hline NM_029000 & $\begin{array}{l}\text { M. musculus GTPase, very large IFN-inducible } 1 \text { (Gvin1), transcript variant 1, mRNA } \\
\text { [NM_029000] }\end{array}$ & Gvin1 & 6.16 & 5.74 & 1.07 \\
\hline NM_013585 & $\begin{array}{l}\text { M. musculus proteasome (prosome, macropain) subunit, beta type } 9 \text { (large multifunctional } \\
\text { peptidase 2) (Psmb9), mRNA [NM_013585] }\end{array}$ & Psmb9 & 6.16 & 3.51 & 1.76 \\
\hline NM_001146007 & $\begin{array}{l}\text { M. musculus tripartite motif-containing 12C (Trim12C), transcript variant 1, mRNA } \\
\text { [NM_001146007] }\end{array}$ & Trim12c & 6.11 & 5.41 & 1.13 \\
\hline NM_023141 & M. musculus torsin family 3, member A (Tor3a), mRNA [NM_023141] & Tor3a & 6.11 & 5.96 & 1.03 \\
\hline NR_030671 & $\begin{array}{l}\text { M. musculus expressed sequence AW011738 (AW011738), long non-coding RNA } \\
\text { [NR_030671] }\end{array}$ & AW01173 8 & 6.11 & 7.36 & 0.83 \\
\hline NM_021274 & M. musculus chemokine (C-X-C motif) ligand 10 (Cxcl10), mRNA [NM_021274] & $\mathrm{Cxcl} 10$ & 6.10 & 4.89 & 1.25 \\
\hline NM_001025208 & M. musculus MHC class I family member (LOC547349), mRNA [NM_001025208] & LOC5473 49 & 6.10 & 4.08 & 1.49 \\
\hline NM_030253 & M. musculus poly (ADP-ribose) polymerase family, member 9 (Parp9), mRNA [NM_030253] & Parp9 & 6.04 & 6.28 & 0.96 \\
\hline NM_001162938 & M. musculus pyrin domain containing 3 (Pydc3), mRNA [NM_001162938] & Pydc3 & 6.03 & 2.21 & 2.72 \\
\hline
\end{tabular}

\section{Cell-Type Specificity of the IFN- $\lambda$-Induced Transcriptional Profile}

Dendritic cells were reported to respond to type III IFN $(14,38)$. Therefore, BMDCs were examined following stimulation with IFN- $\beta(500 \mathrm{U} / \mathrm{mL})$ or IFN- $\lambda_{2}(20 \mathrm{ng} / \mathrm{mL})$ for $9 \mathrm{~h}$ by RT-PCR. Expression of the prototypical ISGs Usp18, Ifi44, and Ifit1 was increased following exposure to IFN- $\beta$. By contrast, no influence of IFN- $\lambda_{2}$ on the expression level of Usp18, Ifi44, and Ifit1
(Figure 3A) or the expression level of Mmp7, Serpinb1a, and Csprs was observed (Figure 3B). To determine if the predominantly IFN- $\lambda_{2}$-induced gene signature was restricted to the epithelial cells of the intestine, we next analyzed epithelial cells of another important mucosal organ, the lung. Lung epithelial cells have previously been reported to express receptors for both, type I and type III IFNs. Primary lung epithelial cells cultured for 5 days before stimulation were analyzed. Stimulation with IFN- $\beta$ (500 U/ 

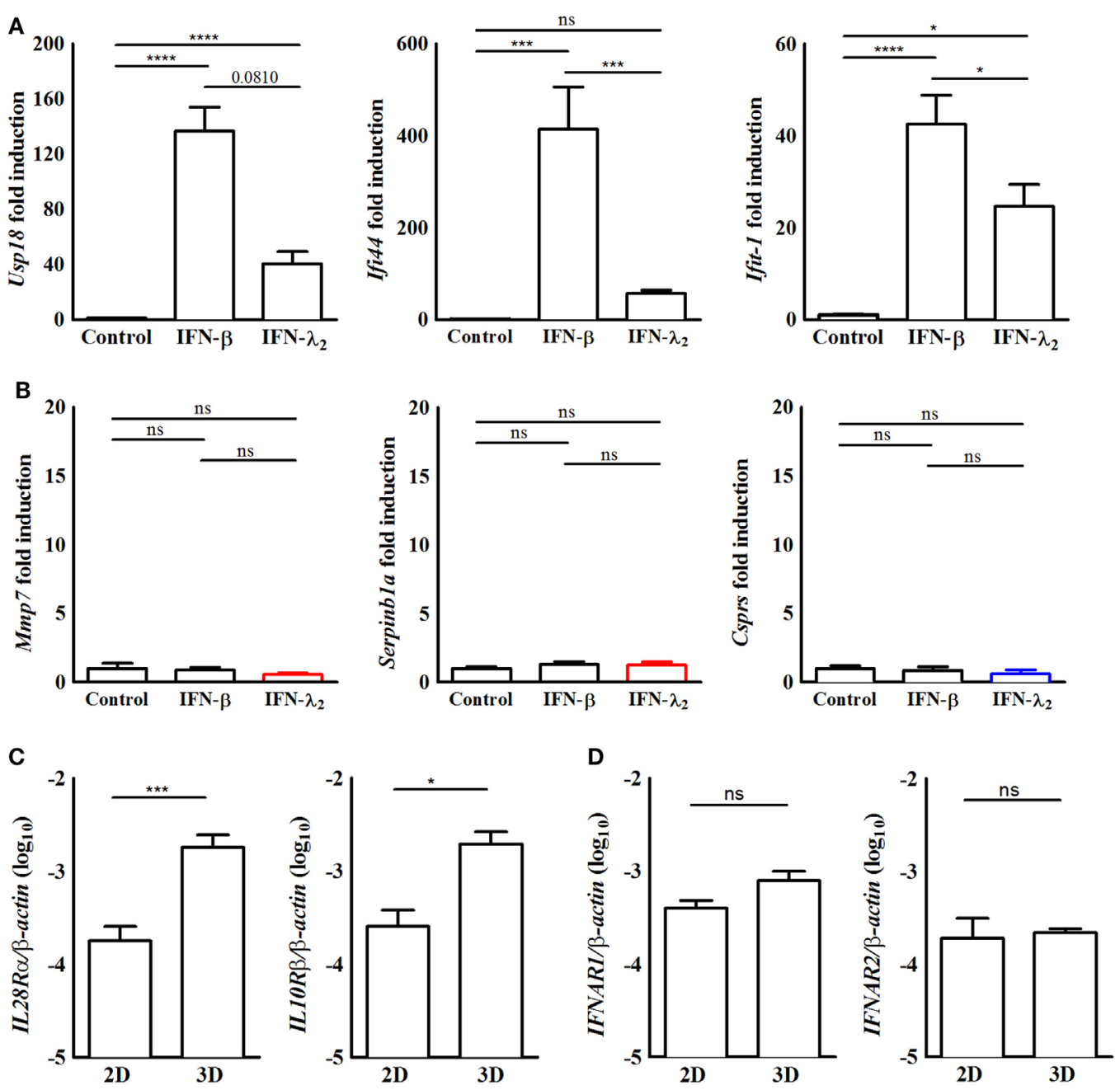

FIGURE 2 | The induction of predominantly interferon (IFN)- $\lambda_{2}$-induced genes requires epithelial polarization. $(\mathbf{A}, \mathbf{B})$ Quantitative RT-PCR for $(\mathbf{A})$ the prototypical IFN-stimulated genes (ISGs) Usp18, Ifi44, and Ifit1 or (B) the predominantly IFN- $\lambda$-induced ISGs Mmp7, Serpinb1a, and Csprs performed on total RNA isolated from IEC10 cells grown in conventional flat bottom 12-well tissue culture plates under 2D conditions and stimulated for $9 \mathrm{~h}$ with IFN- $\lambda_{2}$ (20 ng/mL) or IFN- $\beta$ (500 U/mL). The results represent the mean \pm SEM values from two independent experiments and are normalized to the values obtained for the housekeeping gene $\beta$-actin. Statistical significance was calculated using a one-way analysis of variance (with Tukey's posttest). (C,D) Quantitative RT-PCR for (C) IL-28R $\alpha$ and IL-10 receptor $(\mathrm{IL}-1 \mathrm{OR}) \beta$ and (D) IFNAR1 and IFNAR2 performed on total RNA isolated from unstimulated IEC10 cells grown either on conventional flat bottom tissue culture plates (2D) or transwell inserts (3D). The results are normalized to the values obtained for $\beta$-actin and are represented as mean \pm SEM values from two independent experiments performed in quadruplicates. Statistical significance was calculated using the Mann-Whitney $U$ test.

$\mathrm{mL})$ or IFN- $\lambda_{2}(20 \mathrm{ng} / \mathrm{mL})$ for $9 \mathrm{~h}$ induced a significant increase of the prototypical ISGs Usp18, Ifi44, and Ifit1 (Figure 3C) but failed to enhance the expression level of Mmp7 and Serpinb1a (Figure 3D). Csprs expression was significantly enhanced by IFN- $\beta$ but not IFN $-\lambda_{2}$ indicating a more pronounced effect of IFN $-\lambda_{2}$ on intestinal as compared with lung epithelial cells.

\section{In Vivo Induction of the IFN- $\lambda_{2}$ Stimulated Gene Signature}

To confirm expression of the predominantly IFN- $\lambda$-induced genes in vivo, 8-week-old IFNAR1-deficient female mice were intraperitoneally stimulated with $1 \mu \mathrm{g}$ murine IFN $-\lambda_{2} .9 \mathrm{~h}$ after administration, intestinal epithelial cells were prepared and analyzed by RT-PCR. IFN- $\lambda_{2}$ administration significantly enhanced expression of the prototypic ISG Ifit1 (Figure 4A). It also significantly enhanced the expression level of the predominantly IFN- $\lambda$-induced genes $M m p 7$ (Figure 4B) and Serpinb1a (Figure 4C). By contrast, intraperitoneal administration of $500 \mathrm{U}$ IFN- $\beta$ to IL-28R deficient failed to induce the prototypic ISG Ifit1 (Figure 4D). Also, neither an increase of Mmp7 (Figure 4E) nor Serpinbla expression was observed (Figure 4F). Immunostaining subsequently confirmed induction of the prototypic ISG IFIT1 in the intestinal villus epithelium of IFN- $\lambda_{2}$ treated IFNAR1-deficient animals (Figure 4G). Finally, also enhanced expression of the predominantly IFN- $\lambda_{2}$-induced target MMP7 was noted in crypt based Paneth cells of IFNAR1-deficient animals following IFN- $\lambda_{2}$ administration (Figure $4 \mathrm{H}$ ). 


\section{A Bone Marrow Derived Dendritic Cells}
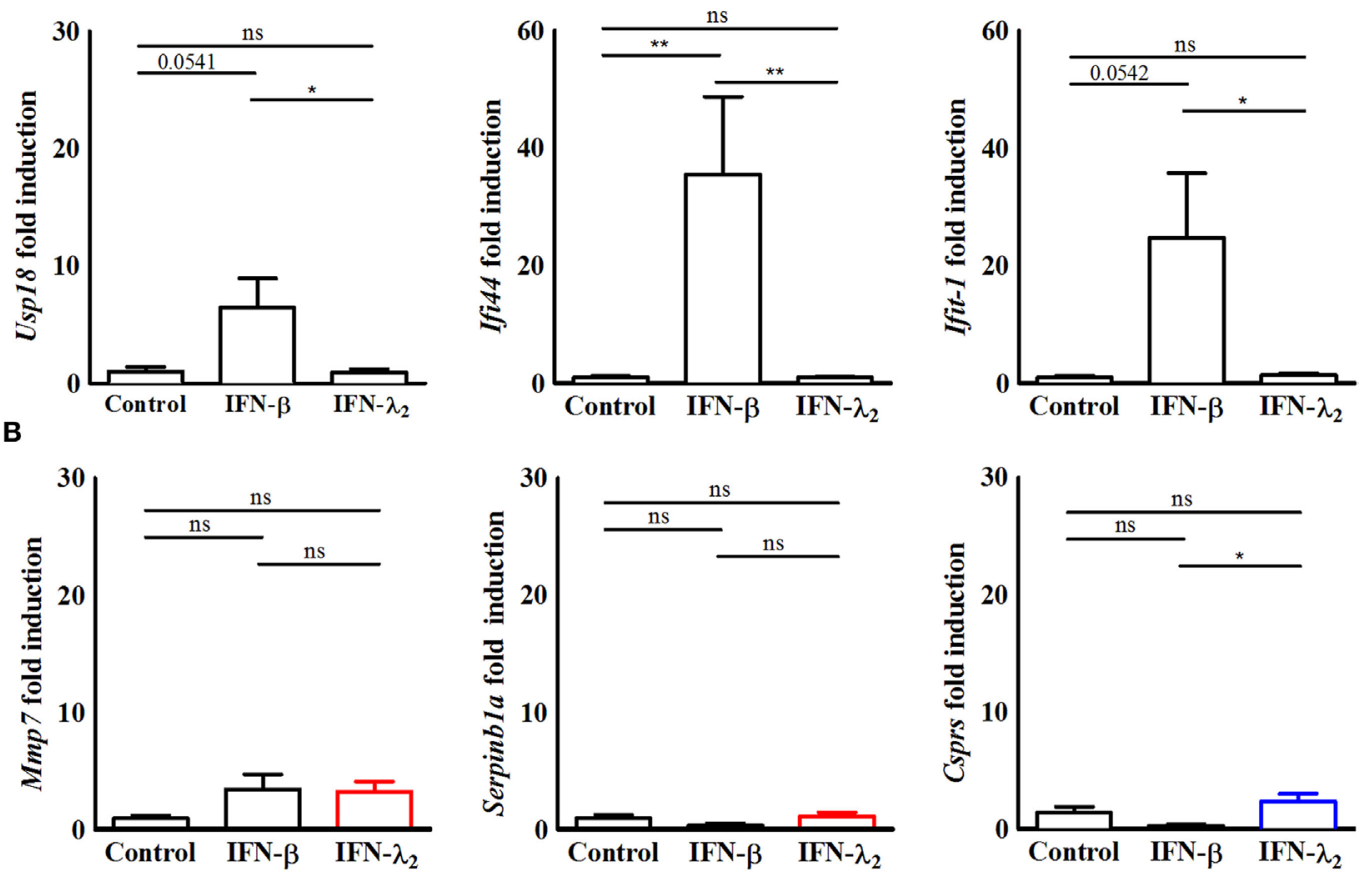

C
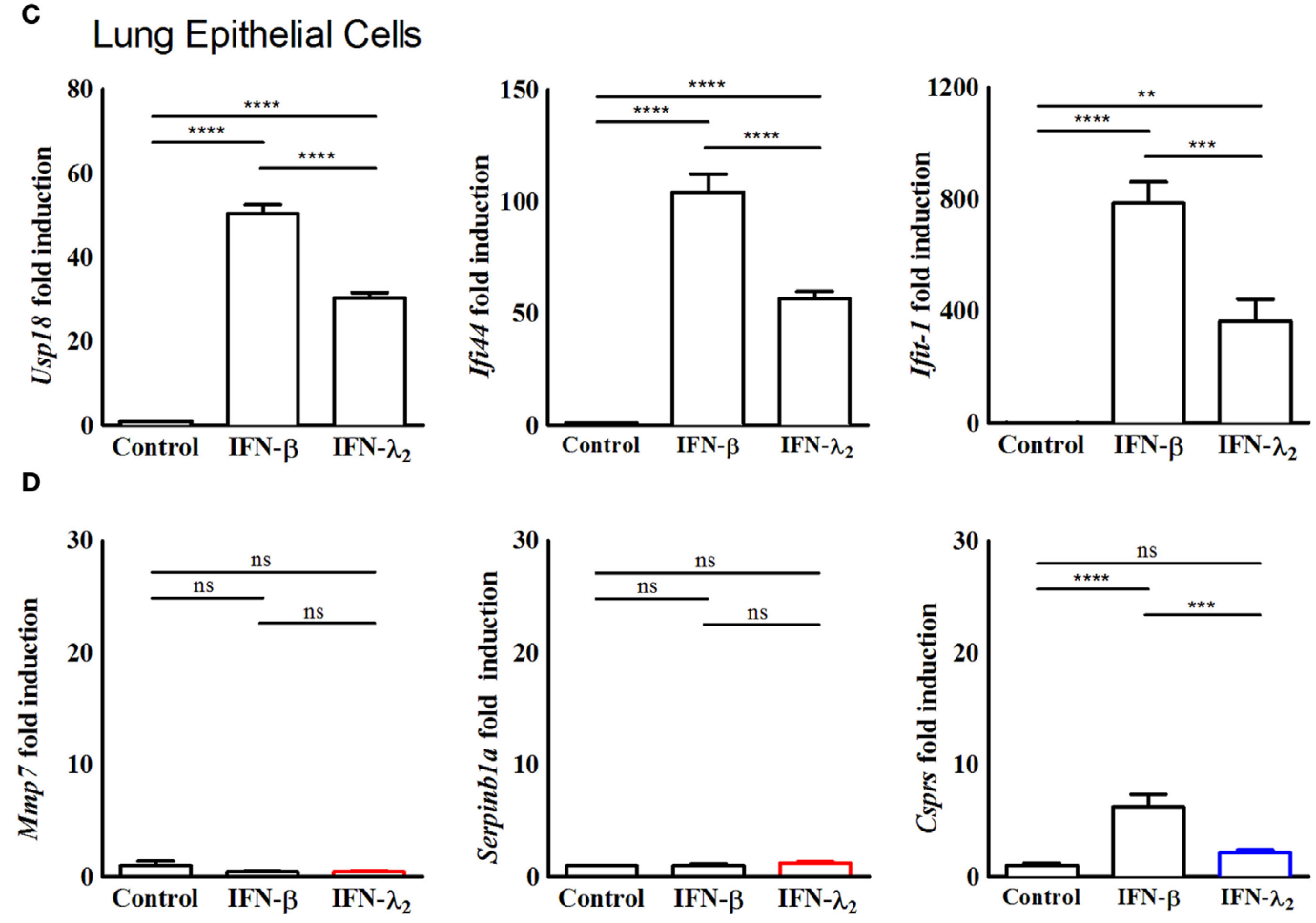

FIGURE 3 | Predominantly interferon (IFN)- $\lambda$-induced genes are not induced in bone marrow-derived dendritic cells and primary lung epithelial cells. (A,B) Quantitative RT-PCR for (A) the prototypical IFN-stimulated genes (ISGs) Usp18, Ifi44, and Ifit1 and (B) the predominantly IFN- $\lambda$-induced ISGs Mmp7, Serpinb1a, and Csprs performed on total RNA isolated from bone marrow-derived dendritic cells isolated from 8-week-old female wild-type mice and cultured in vitro for 7 days. The dendritic cells were stimulated with Flt3 ligand to initiate maturation, following which they were stimulated with IFN- $\lambda_{2}(20 \mathrm{ng} / \mathrm{mL}$ ) or IFN- $\beta$ (500 U/mL) for 9 h. (C,D) Quantitative RT-PCR for (C) the prototypical ISGs Usp18, Ifi44, and Ifit1 and (D) the predominantly IFN- $\lambda$-induced ISGs Mmp7 and Serpinb1a and Csprs performed on total RNA isolated from primary lung epithelial cells isolated from 8-week-old female wild-type mice and cultured in vitro for 5 days before stimulation for $9 \mathrm{~h}$ with IFN- $\lambda_{2}(20 \mathrm{ng} / \mathrm{mL})$ or IFN- $\beta(500 \mathrm{U} / \mathrm{mL})$. The results are normalized to $\beta$-actin and are represented as mean \pm SEM values from two independent experiments performed in quadruplicates. Statistical significance was calculated using a one-way analysis of variance (with Tukey's posttest). 

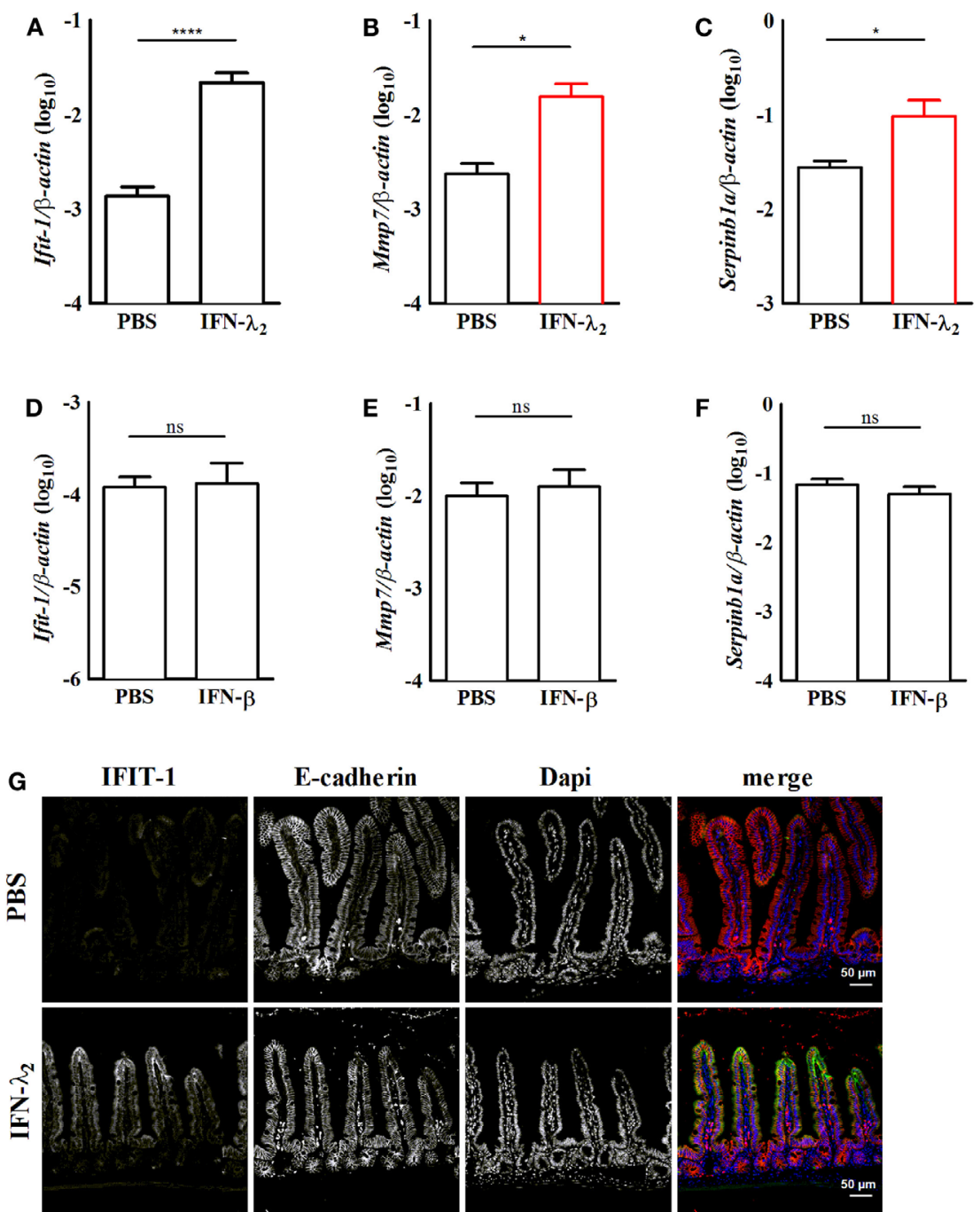

E-cadherin
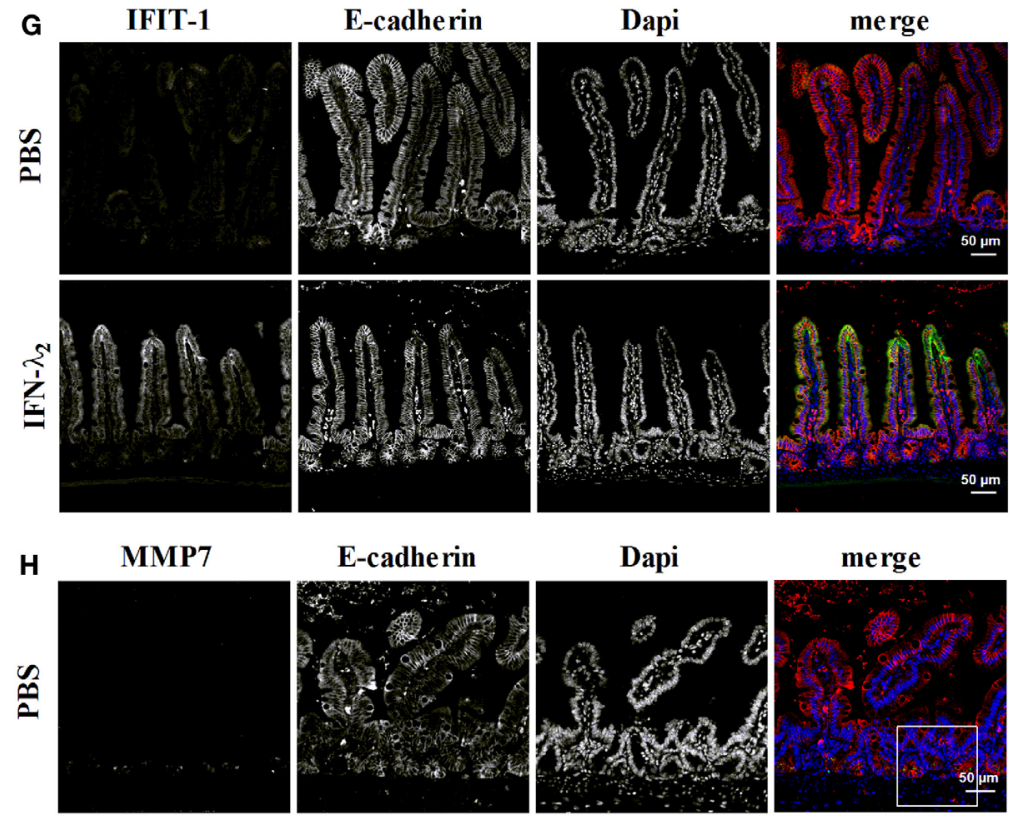

E-cadherin

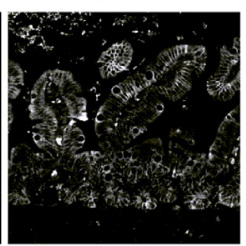

Dapi

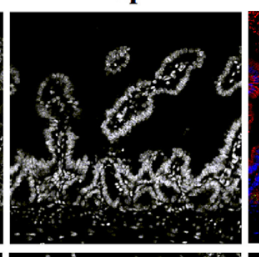

merge

zoom
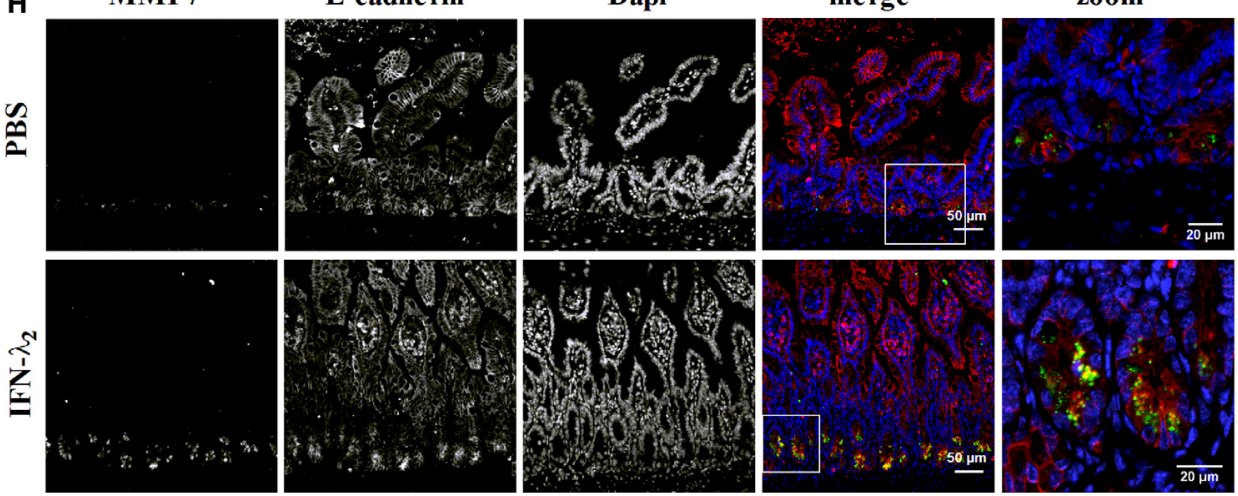

FIGURE 4 | In vivo confirmation of the expression of predominantly interferon (IFN)- $\lambda_{2}$-induced genes in the intestinal epithelium. Primary intestinal epithelial cells were isolated from IFNAR1 ${ }^{-/-}$(A-C) or IL28R ${ }^{-/-}$(D-F) female 8-week-old adult mice $9 \mathrm{~h}$ after intraperitoneal injection of IFN- $\lambda_{2}[1 \mu \mathrm{g}$, (A)] or IFN- $\beta$ [500 U, (D)], respectively. Control animals in each group received PBS. Quantitative RT-PCR for the prototypical IFN-stimulated gene (ISG) lfit1 [(A), $n=12$ animals per group; (D), $n=8$ animals per group], the predominantly IFN- $\lambda_{2}$-induced ISGs Mmp7 [(B), $n=8$ animals per group; (E), 8 animals per group] and Serpinb1a [(C), $n=12$ animals per group; (F), 8 animals per group] performed on total RNA prepared from primary intestinal epithelial cells. Epithelial cells were isolated from PBS or IFN- $\lambda_{2}$ treated IFNAR1 $1^{-/}$mice or PBS or IFN- $\beta$ treated IL28R ${ }^{-/-}$animals. The results are normalized to $\beta$-actin and are represented as mean \pm SEM from two to three independent experiments. Statistical analysis was performed using the Mann-Whitney $U$ test. $(\mathbf{G}, \mathbf{H})$ Paraffin-embedded samples from IFNAR1 ${ }^{-/-}$mice treated with PBS or IFN- $\lambda_{2}$ as indicated were subjected to simultaneous staining for (G) IFIT1 (green) and E-cadherin (red) or for (H) MMP7 (green) and E-cadherin (red). Counterstaining was performed with DAPI (blue). White squares depict the zoomed area of the merged images in panel (H). Scale 50 and $20 \mu \mathrm{m}$ in the zoomed areas. 


\section{DISCUSSION}

The major biological difference between type I and type III IFN was shown to reside in their organ and cell-type tropism. Whereas most nucleated cells respond to type I IFN, type III IFN appears to play a non-redundant role in the protection of epithelial cells at mucosal body sites such as the gastrointestinal and respiratory tract in vivo $(8,9,18)$. This renders type III IFNs critical components of the epithelial antiviral host response and raises the question of the evolutionary benefit of an additional epitheliumspecific IFN system. First, an epithelium-specific antiviral host response acts early during the infectious challenge and may be able to cope with the microbial challenge in the absence of the wellknown side effects of a systemic IFN response $(39,40)$. Indeed, a recent study demonstrated that the early protective IFN- $\lambda$ effect occurs in the absence of significant tissue inflammation, which might be particularly important in respect to the function of the respiratory and gastrointestinal tract (22). Consistently, IFN- $\lambda$ has been shown to also exert an immunomodulatory effect on PMNs $(15,16)$. The use of IFN- $\lambda$ as an alternative therapeutic option to type I IFN has been therefore suggested for human viral hepatitis in an attempt to reduce the systemic side effects (41). Second, type III IFN may be able to simultaneously induce gene products that tailor the response to fit the needs of an anti-infectious host response at colonized mucosal surfaces.

Previous studies did not identify a type III IFN-specific gene profile $(12,20,24-30)$. Notably, however, these studies employed hepatocytes or immortalized liver cell lines as well as lung epithelial cells possibly missing out on genes involved to maintain host-microbial homeostasis at the most densely colonized body surface, the intestinal tract. The striking species-specific activity of type III IFN on human but not mouse hepatocytes underlines the exceptional phenotype of hepatocytes (42). Also, our results revealed no expression of the predominantly IFN- $\lambda$-induced genes in lung epithelial cells. Intestinal epithelial cells might therefore represent the most promising cell type to investigate an IFN- $\lambda_{2}$-specific cell response. Indeed, differences in the IFN receptor signal cascade have previously been observed between different cell types $(12,23,43)$.

In this study, we employed a recently described immortalized intestinal epithelial cell line that exhibits a potent response to both type I and III IFN (32). These cells express a number of typical intestinal epithelial cell marker proteins and exhibit a polarized growth with increase in the transepithelial electrical resistance when cultured on porous transwell culture surfaces. Most importantly, stimulation of ISGs in IEC10 cells was induced by both, type I and III IFN in a dose-dependent manner. This cell-culture model therefore represents an ideal tool to investigate the differential response to type I versus type III IFN at the intestinal epithelial lining. In addition, we employed IL-28R and IFNAR-deficient animals in combination with protocols to isolate highly enriched primary gut epithelial cells to confirm the induction of a predominantly IFN- $\lambda$-induced gene, $M m p 7$, in vivo (9).

Comparative analysis of IFN- $\beta$ versus IFN- $\lambda_{2}$ stimulated IEC10 cells resulted in the identification of a predominantly IFN- $\lambda_{2}$-induced gene expression profile. The identified genes do not belong to the previously defined group of classical ISGs associated with viral inhibition but their function demonstrates a clear association with the gut epithelial barrier function. MMP7 plays a critical role in tissue remodeling, encodes an immunomodulatory activity and activates Paneth cell-derived antimicrobial peptides (44). Other gene products such as the vitamin A transporter transthyretin, the $\mathrm{Na}^{+} \mathrm{HCO}_{3}^{-}$ cotransporter NBCn1 (Slc4a7), the surface membrane protein annexin A13 or the $\mathrm{Na}$ channel $\alpha-\mathrm{ENaC}$ (encoded by Scnn1A) may contribute to metabolism, transcellular transport and ion homeostasis at the epithelium $(45,46)$. The dynein protein Dnah7b (dynein axonemal heavy chain 7B) the mucin-synthesis core 2 1,6-N-acetylglucosaminyltransferase enzyme (C2GnT-M encoded by the GCNT3 gene) and the desmosome protein premature ovarian failure $1 \mathrm{~B}$ (Pof1b) may reinforce epithelial barrier formation (47-49). Other proteins such as the HIF1associated regulator paired-like homeodomain pituitary transcription factor Pitx1 or the Ca dependent GTPase RAS protein activator (Rasal1) may be involved to tailor cellular functions and epithelial gene expression $(50,51)$. Thus, enhanced expression of predominantly IFN- $\lambda_{2}$-induced gene products may help to control the inflammatory reaction at impaired mucosal body sites and reconstitute the epithelial barrier integrity and hostmicrobial homeostasis following viral clearance.

This hypothesis is also consistent with the fact that type III IFNs belong to the IL-10 cytokine family, a large group of cytokines that also includes IL-10, IL-19, IL-20, IL-22, IL-24, and IL-26. Members of this family play a critical role in the maintenance and repair of the epithelial barrier function during infectious and inflammatory challenges (52). They exhibit a strong immunomodulatory activity illustrating the adverse effect of uncontrolled mucosal inflammation and the need to maintain the integrity of body surfaces and host-microbial homeostasis. This is nicely illustrated by IL-10 that is able to repress proinflammatory responses playing a critical role to maintain mucosal homeostasis in the colon (53). Also, IL-22 strengthens the mucosal barrier and induces antibacterial effector molecules in the absence of an inflammatory response. Of note, IL-22 and type III IFN were recently shown to synergize to restrict viral replication at the intestinal epithelium (54).

Cell polarization appears to play a critical role for the expression of the predominantly IFN- $\lambda_{2}$-induced gene profile. Apical-basolateral polarization represents a key feature of intestinal epithelial cells and has previously been functionally associated with the response of gut epithelial cells to IFN (9). Strikingly, epithelial cell polarization significantly enhanced the expression level of the IL-28R $\alpha$ chain but not of the IFNAR receptor complex confirming a previous report (37). It is therefore tempting to speculate on a possible functional link between the level of expression of the type III IFN receptor and the ability to induce additional cellular signal transduction pathways ultimately inducing a predominantly IFN- $\lambda_{2}$-induced gene profile. Alternatively, the cell polarization itself may influence downstream events of the IL-28 receptor complex. Future investigations will be needed to identify and dissect the involved signaling pathways.

In conclusion, we here report on the first evidence for the existence of a predominantly IFN- $\lambda_{2}$-induced gene expression profile in 
polarized intestinal epithelial cells in vitro and in vivo. Expression of predominantly IFN- $\lambda_{2}$-induced genes was restricted to gut epithelial cells and required apical-basolateral cell polarization. The existence of a predominantly IFN- $\lambda$-induced gene set at the intestinal epithelium might significant extend the biological role of IFN- $\lambda$ and shed light on the particular situation at microbially colonized mucosal surfaces during infectious challenges.

\section{ETHICS STATEMENT}

All animal experiments were performed in compliance with the German animal protection law (TierSchG) and approved by the local animal welfare committee Niedersächsisches Landesamt für Verbraucherschutz und Lebensmittelsicherheit Oldenburg, Germany. Mice were housed under specific pathogen-free conditions and handled in accordance with regulations defined by FELASA and the national animal welfare body GV-SOLAS (www.gv-solas.de/index.html).

\section{AUTHOR CONTRIBUTIONS}

TS, SB, MK, and MH performed experiments. TS, SB, MK, DW, $\mathrm{HH}$, and $\mathrm{MH}$ planned the experiments and evaluated the results. $\mathrm{HH}, \mathrm{MK}$, and UK provided critical reagents. TS, MK, DW, HH, $\mathrm{UK}$, and $\mathrm{MH}$ wrote the manuscript.

\section{ACKNOWLEDGMENTS}

This work was supported by the European Research Training Group 1273 "Strategies of human pathogens to establish acute and chronic infections" funded by the German Research Foundation (to TS) as well as the grants Ho-2236/12-1, Ho-2236/8-1, and Ho-2236/14-1 to MH. The microarray analysis was performed by Oliver Dittrich-Breiholz from the Transcriptomics core facility of Hannover Medical School, Hannover, Germany. The authors gratefully acknowledge the technical support from Dominique Gütle, Thorben Albers, and Mathias Riehn.

\section{FUNDING}

$\mathrm{MK}$ and $\mathrm{HH}$ were supported by BMBF collaborative project ImmunoQuant (e:Bio, grant number: 0316170T) and $\mathrm{MK}, \mathrm{HH}$,

\section{REFERENCES}

1. Isaacs A, Lindemann J. Virus interference. I. The interferon. Proc R Soc Lond B Biol Sci (1957) 147:258-67. doi:10.1098/rspb.1957.0048

2. Kotenko SV, Gallagher G, Baurin VV, Lewis-Antes A, Shen M, Shah NK, et al. IFN-lambdas mediate antiviral protection through a distinct class II cytokine receptor complex. Nat Immunol (2003) 4:69-77. doi:10.1038/ni875

3. Sheppard P, Kindsvogel W, Xu W, Henderson K, Schlutsmeyer S, Whitmore TE, et al. IL-28, IL-29 and their class II cytokine receptor IL-28R. Nat Immunol (2003) 4:63-8. doi:10.1038/ni873

4. Thomson SJ, Goh FG, Banks H, Krausgruber T, Kotenko SV, Foxwell BM, et al. The role of transposable elements in the regulation of IFN-lambdal gene expression. Proc Natl Acad Sci U S A (2009) 106:11564-9. doi:10.1073/ pnas.0904477106

5. Osterlund PI, Pietilä TE, Veckman V, Kotenko SV, Julkunen I. IFN regulatory factor family members differentially regulate the expression of type and $\mathrm{MH}$ by the Collaborative Research Center SFB900 (Chronic Infection: Microbial Persistence and Its Control, Project B2 and Project A4). TS was supported by the European Research Training Group 1273 and by the German Research Foundation (DFG). SB was supported by the Infection Biology international PhD program of Hannover Biomedical Research School and by the Helmholtz Centre for Infection Research Graduate School. $\mathrm{MH}$ was supported by the Deutsche Forschungsgemeinschaft (Ho-2236/12-1, Ho-2236/8-1, and Ho-2236/14-1 and Priority Program 1656 and 1580). UK was supported by funding from the Helmholtz-Alberta Initiative, Infectious Diseases Research (HAI-IDRSO-073).

\section{SUPPLEMENTARY MATERIAL}

The Supplementary Material for this article can be found online at http://www.frontiersin.org/article/10.3389/fimmu.2017.01302/ full\#supplementary-material.

FIGURE S1 | Interferon (IFN) effect on house-keeping gene expression and time kinetic of IFN- $\beta$ and IFN- $\lambda_{2}$-induced IFN-stimulated gene induction. (A) mRNA expression (intensity) of the house-keeping gene $\beta$-actin in unstimulated IEC10 cells (control) and IEC10 cells stimulated with IFN- $\beta(500 \mathrm{U} / \mathrm{mL})$ and IFN- $\lambda_{2}$ $(20 \mathrm{ng} / \mathrm{mL})$ for $9 \mathrm{~h}$. The results represent the mean $\pm \mathrm{SEM}$ values from one experiment performed in triplicates. (B) IEC10 cells carrying an Mx2-luciferase reporter were stimulated with IFN- $\beta(500 \mathrm{U} / \mathrm{mL})$ and IFN- $\lambda_{2}(20 \mathrm{ng} / \mathrm{mL})$ for the indicated time periods and the luciferase production was determined. The data are presented as mean \pm SD from one experiment performed in triplicates.

FIGURE S2 | Gene induction by interferon (IFN)- $\lambda_{2}$ in IEC10 cells.

(A) Heatmap of stimulated genes in IEC10 cells cultured on transwell filter inserts and left untreated (PBS) or exposed to IFN- $\lambda_{2}(20 \mathrm{ng} / \mathrm{mL})$ or IFN- $\beta(500 \mathrm{U} / \mathrm{mL})$ for $9 \mathrm{~h}$. Data were obtained using a global gene expression array. Two-group analysis for the induction of IFN- $\lambda_{2}$-induced genes were carried out at $p=0.001$, $q=0.05, F C=2$ represented as a hierarchical cluster of 349 genes upregulated by IFN- $\lambda_{2}$. (B-D) Clusters of orthologous group analysis of the (B) "predominantly IFN- $\lambda_{2}$-induced genes," (C) "strongly IFN- $\lambda_{2}$-induced genes," and (D) "classical antiviral IFN-stimulated genes," shown in Figure 1C

FIGURE S3 | Early time kinetic of interferon (IFN)- $\beta$ and IFN- $\lambda_{2}$-induced IFN-stimulated gene (ISG) induction. (A,B) Quantitative RT-PCR for the prototypical ISGs Usp18 and Ifi44 as well as the predominantly IFN- $\lambda_{2}$-induced ISGs Mmp7 and Serpinb1a performed on total RNA isolated from IEC10 cells grown on transwell filter inserts and stimulated with (A) IFN- $\beta(500 \mathrm{U} / \mathrm{mL})$ and (B) IFN- $\lambda_{2}(20 \mathrm{ng} / \mathrm{mL})$ for the indicated time periods. The results represent the mean \pm SEM values from one experiment performed in triplicates and are normalized to the values obtained for the housekeeping gene $\beta$-actin.

III IFN (IFN-lambda) genes. J Immunol (2007) 179:3434-42. doi:10.4049/ jimmunol.179.6.3434

6. Onoguchi K, Yoneyama M, Takemura A, Akira S, Taniguchi T, Namiki H, et al. Viral infections activate types I and III interferon genes through a common mechanism. J Biol Chem (2007) 282:7576-81. doi:10.1074/jbc. M608618200

7. Odendall C, Dixit E, Stavru F, Bierne H, Franz KM, Durbin AF, et al. Diverse intracellular pathogens activate type III interferon expression from peroxisomes. Nat Immunol (2014) 15:717-26. doi:10.1038/ni.2915

8. Mahlakõiv T, Hernandez P, Gronke K, Diefenbach A, Staeheli P. Leukocytederived IFN- $\alpha / \beta$ and epithelial IFN- $\lambda$ constitute a compartmentalized mucosal defense system that restricts enteric virus infections. PLoS Pathog (2015) 11:e1004782. doi:10.1371/journal.ppat.1004782

9. Pott J, Mahlakõiv T, Mordstein M, Duerr CU, Michiels T, Stockinger S, et al. IFN- $\lambda$ determines the intestinal epithelial antiviral host defense. Proc Natl Acad Sci U S A (2011) 108:7944-9. doi:10.1073/pnas.1100552108 
10. Sommereyns C, Paul S, Staeheli P, Michiels T. IFN-lambda (IFN- $\lambda$ ) is expressed in a tissue-dependent fashion and primarily acts on epithelial cells in vivo. PLoS Pathog (2008) 4:e1000017. doi:10.1371/journal.ppat.1000017

11. Ank N, Iversen MB, Bartholdy C, Staeheli P, Hartmann R, Jensen UB, et al. An important role for type III interferon (IFN-lambda/IL-28) in TLR-induced antiviral activity. J Immunol (2008) 180:2474-85. doi:10.4049/ jimmunol.180.4.2474

12. Zhou Z, Hamming OJ, Ank N, Paludan SR, Nielsen AL, Hartmann R. Type III interferon (IFN) induces a type I IFN-like response in a restricted subset of cells through signaling pathways involving both the Jak-STAT pathway and the mitogen-activated protein kinases. J Virol (2007) 81:7749-58. doi:10.1128/ JVI.02438-06

13. Souza-Fonseca-Guimaraes F, Young A, Mittal D, Martinet L, Bruedigam C, Takeda K, et al. NK cells require IL-28R for optimal in vivo activity. Proc Natl Acad Sci U S A (2015) 112:E2376-84. doi:10.1073/pnas.1424241112

14. Kelly A, Robinson MW, Roche G, Biron CA, O’Farrelly C, Ryan EJ. Immune cell profiling of IFN- $\lambda$ response shows pDCs express highest level of IFN- $\lambda$ R1 and are directly responsive via the JAK-STAT pathway. J Interferon Cytokine Res (2016) 36:671-80. doi:10.1089/jir.2015.0169

15. Broggi A, Tan Y, Granucci F, Zanoni I. IFN- $\lambda$ suppresses intestinal inflammation by non-translational regulation of neutrophil function. Nat Immunol (2017) 18(10):1084-93. doi:10.1038/ni.3821

16. Chrysanthopoulou A, Kambas K, Stakos D, Mitroulis I, Mitsios A, Vidali V, et al. Interferon lambda1/IL-29 and inorganic polyphosphate are novel regulators of neutrophil-driven thromboinflammation. J Pathol (2017) 243(1):111-22. doi:10.1002/path.4935

17. Mordstein M, Kochs G, Dumoutier L, Renauld JC, Paludan SR, Klucher $\mathrm{K}$, et al. Interferon-lambda contributes to innate immunity of mice against influenza A virus but not against hepatotropic viruses. PLoS Pathog (2008) 4:e1000151. doi:10.1371/journal.ppat.1000151

18. Mordstein M, Neugebauer E, Ditt V, Jessen B, Rieger T, Falcone V, et al. Lambda interferon renders epithelial cells of the respiratory and gastrointestinal tracts resistant to viral infections. J Virol (2010) 84:5670-7. doi:10.1128/ JVI.00272-10

19. Pulverer JE, Rand U, Lienenklaus S, Kugel D, Zietara N, Kochs G, et al. Temporal and spatial resolution of type I and III interferon responses in vivo. J Virol (2010) 84:8626-38. doi:10.1128/JVI.00303-10

20. Lin JD, Feng N, Sen A, Balan M, Tseng HC, McElrath C, et al. Distinct roles of type I and type III interferons in intestinal immunity to homologous and heterologous rotavirus infections. PLoS Pathog (2016) 12:e1005726. doi:10.1371/ journal.ppat. 1005726

21. Baldridge MT, Lee S, Brown JJ, McAllister N, Urbanek K, Dermody TS, et al. Expression of Ifnlr1 on intestinal epithelial cells is critical to the antiviral effects of interferon lambda against norovirus and reovirus. J Virol (2017) 91:e2079-2016. doi:10.1128/JVI.02079-16

22. Galani IE, Triantafyllia V, Eleminiadou EE, Koltsida O, Stavropoulos A, Manioudaki $\mathrm{M}$, et al. Interferon- $\lambda$ mediates non-redundant front-line antiviral protection against influenza virus infection without compromising host fitness. Immunity (2017) 46:875-90. doi:10.1016/j.immuni.2017. 04.025

23. Brand S, Beigel F, Olszak T, Zitzmann K, Eichhorst ST, Otte JM, et al. IL-28A and IL-29 mediate antiproliferative and antiviral signals in intestinal epithelial cells and murine CMV infection increases colonic IL-28A expression. Am J Physiol Gastrointest Liver Physiol (2005) 289:G960-8. doi:10.1152/ ajpgi.00126.2005

24. Doyle SE, Schreckhise H, Khuu-Duong K, Henderson K, Rosler R, Storey H, et al. Interleukin- 29 uses a type 1 interferon-like program to promote antiviral responses in human hepatocytes. Hepatology (2006) 44:896-906. doi:10.1002/ hep. 21312

25. Marcello T, Grakoui A, Barba-Spaeth G, Machlin ES, Kotenko SV, MacDonald MR, et al. Interferons alpha and lambda inhibit hepatitis $\mathrm{C}$ virus replication with distinct signal transduction and gene regulation kinetics. Gastroenterology (2006) 131:1887-98. doi:10.1053/j.gastro.2006.09.052

26. Kohli A, Zhang X, Yang J, Russell RS, Donnelly RP, Sheikh F, et al. Distinct and overlapping genomic profiles and antiviral effects of interferon- $\lambda$ and $-\alpha$ on HCV-infected and noninfected hepatoma cells. J Viral Hepat (2012) 19:843-53. doi:10.1111/j.1365-2893.2012.01610.x

27. Crotta S, Davidson S, Mahlakoiv T, Desmet CJ, Buckwalter MR, Albert ML, et al. Type I and type III interferons drive redundant amplification loops to induce a transcriptional signature in influenza-infected airway epithelia. PLoS Pathog (2013) 9:e1003773. doi:10.1371/journal.ppat.1003773

28. Jilg N, Lin W, Hong J, Schaefer EA, Wolski D, Meixong J, et al. Kinetic differences in the induction of interferon stimulated genes by interferon- $\alpha$ and IL28B are altered by infection with hepatitis C virus. Hepatology (2014) 59:1250-61. doi:10.1002/hep.26653

29. Bolen CR, Ding S, Robek MD, Kleinstein SH. Dynamic expression profiling of type I and type III interferon-stimulated hepatocytes reveals a stable hierarchy of gene expression. Hepatology (2014) 59:1262-72. doi:10.1002/hep.26657

30. Lauber C, Vieyres G, Terczyńska-Dyla E, Anggakusuma, Dijkman R, Gad HH, et al. Transcriptome analysis reveals a classical interferon signature induced by IFN $\lambda 4$ in human primary cells. Genes Immun (2015) 16:414-21. doi:10.1038/ gene.2015.23

31. Meager A, Visvalingam K, Dilger P, Bryan D, Wadhwa M. Biological activity of interleukins-28 and -29: comparison with type I interferons. Cytokine (2005) 31:109-18. doi:10.1016/j.cyto.2005.04.003

32. Schwerk J, Köster M, Hauser H, Rohde M, Fulde M, Hornef MW, et al. Generation of mouse small intestinal epithelial cell lines that allow the analysis of specific innate immune functions. PLoS One (2013) 8:e72700. doi:10.1371/ journal.pone. 0072700

33. Nice TJ, Baldridge MT, McCune BT, Norman JM, Lazear HM, Artyomov $\mathrm{M}$, et al. Interferon- $\lambda$ cures persistent murine norovirus infection in the absence of adaptive immunity. Science (2015) 347:269-73. doi:10.1126/science. 1258100

34. Chiriac MT, Buchen B, Wandersee A, Hundorfean G, Günther C, Bourjau Y, et al. Activation of epithelial signal transducer and activator of transcription 1 by interleukin 28 controls mucosal healing in mice with colitis and is increased in mucosa of patients with inflammatory bowel disease. Gastroenterology (2017) 153:123-38. doi:10.1053/j.gastro.2017.03.015

35. Lotz M, Gütle D, Walther S, Ménard S, Bogdan C, Hornef MW. Postnatal acquisition of endotoxin tolerance in intestinal epithelial cells. J Exp Med (2006) 203:973-84. doi:10.1084/jem.20050625

36. Gereke M, Gröbe L, Prettin S, Kasper M, Deppenmeier S, Gruber AD, et al. Phenotypic alterations in type II alveolar epithelial cells in CD4+ T cell mediated lung inflammation. Respir Res (2007) 8:47. doi:10.1186/ 1465-9921-8-47

37. Bhushal S, Wolfsmüller M, Selvakumar TA, Kemper L, Wirth D, Hornef MW, et al. Cell polarization and epigenetic status shape the heterogeneous response to type III interferons in intestinal epithelial cells. Front Immunol (2017) 8:671. doi:10.3389/fimmu.2017.00671

38. Koltsida O, Hausding M, Stavropoulos A, Koch S, Tzelepis G, Ubel C, et al. IL-28A (IFN- $\lambda 2$ ) modulates lung DC function to promote Th1 immune skewing and suppress allergic airway disease. EMBO Mol Med (2011) 3:348-61. doi:10.1002/emmm.201100142

39. Teles RM, Graeber TG, Krutzik SR, Montoya D, Schenk M, Lee DJ, et al. Type I interferon suppresses type II interferon-triggered human anti-mycobacterial responses. Science (2013) 339:1448-1153. doi:10.1126/science.1233665

40. Rayamajhi M, Humann J, Penheiter K, Andreasen K, Lenz LL. Induction of IFN-alphabeta enables Listeria monocytogenes to suppress macrophage activation by IFN-gamma. J Exp Med (2010) 207:327-37. doi:10.1084/ jem.20091746

41. Lasfar A, Zloza A, Cohen-Solal KA. IFN-lambda therapy: current status and future perspectives. Drug Discov Today (2016) 21:167-71. doi:10.1016/j. drudis.2015.10.021

42. Hermant P, Demarez C, Mahlakõiv T, Staeheli P, Meuleman P, Michiels T. Human but not mouse hepatocytes respond to interferon-lambda in vivo. PLoS One (2014) 9:e87906. doi:10.1371/journal.pone.0087906

43. Guenterberg KD, Grignol VP, Raig ET, Zimmerer JM, Chan AN, Blaskovits FM, et al. Interleukin-29 binds to melanoma cells inducing Jak-STAT signal transduction and apoptosis. Mol Cancer Ther (2010) 9: 510-20. doi:10.1158/1535-7163.MCT-09-0461

44. Vandenbroucke RE, Vanlaere I, Van Hauwermeiren F, Van Wonterghem E, Wilson C, Libert C. Pro-inflammatory effects of matrix metalloproteinase 7 in acute inflammation. Mucosal Immunol (2014) 7:579-88. doi:10.1038/ mi.2013.76

45. Singh AK, Xia W, Riederer B, Juric M, Li J, Zheng W, et al. Essential role of the electroneutral Na+-HCO3-cotransporter NBCn1 in murine duodenal acid-base balance and colonic mucus layer build-up in vivo. J Physiol (2013) 591:2189-204. doi:10.1113/jphysiol.2012.247874 
46. Iglesias JM, Morgan RO, Jenkins NA, Copeland NG, Gilbert DJ, Fernandez MP. Comparative genetics and evolution of annexin A13 as the founder gene of vertebrate annexins. Mol Biol Evol (2002) 19:608-18. doi:10.1093/oxfordjournals.molbev.a004120

47. D’Mello RJ, Caldwell JM, Azouz NP, Wen T, Sherrill JD, Hogan SP, et al. LRRC31 is induced by IL-13 and regulates kallikrein expression and barrier function in the esophageal epithelium. Mucosal Immunol (2016) 9:744-56. doi:10.1038/mi.2015.98

48. Crespi A, Bertoni A, Ferrari I, Padovano V, Della Mina P, Berti E, et al. POF1B localizes to desmosomes and regulates cell adhesion in human intestinal and keratinocyte cell lines. J Invest Dermatol (2015) 135:192-201. doi:10.1038/ jid.2014.327

49. Stone EL, Lee SH, Ismail MN, Fukuda M. Characterization of mice with targeted deletion of the gene encoding core 2 beta1,6-N-acetylglucosaminyltransferase-2. Methods Enzymol (2010) 479:155-72. doi:10.1016/ S0076-6879(10)79009-1

50. Mudie S, Bandarra D, Batie M, Biddlestone J, Moniz S, Ortmann B, et al. PITX1, a specificity determinant in the HIF-1 $\alpha$-mediated transcriptional response to hypoxia. Cell Cycle (2014) 13:3878-91. doi:10.4161/15384101. 2014.972889

51. Jin H, Wang X, Ying J, Wong AHY, Cui Y, Srivastava G, et al. Epigenetic silencing of a $\mathrm{Ca}(2+)$-regulated Ras GTPase-activating protein RASAL defines a new mechanism of Ras activation in human cancers. Proc Natl Acad Sci U S A (2007) 104:12353-8. doi:10.1073/pnas.0700153104
52. Ouyang W, Rutz S, Crellin NK, Valdez PA, Hymowitz SG. Regulation and functions of the IL-10 family of cytokines in inflammation and disease. Annu Rev Immunol (2011) 29:71-109. doi:10.1146/annurev-immunol-031210101312

53. Rennick DM, Fort MM. Lessons from genetically engineered animal models. XII. IL-10-deficient (IL-10 ${ }^{-/}$) mice and intestinal inflammation. Am J Physiol Gastrointest Liver Physiol (2000) 278:G829-33.

54. Hernandez PP, Mahlakoiv T, Yang I, Schwierzeck V, Nguyen N, Guendel F, et al. Interferon- $\lambda$ and interleukin 22 act synergistically for the induction of interferon-stimulated genes and control of rotavirus infection. Nat Immunol (2015) 16:698-707. doi:10.1038/ni.3180

Conflict of Interest Statement: The authors declare that the research was conducted in the absence of any commercial or financial relationships that could be construed as a potential conflict of interest.

Copyright (C) 2017 Selvakumar, Bhushal, Kalinke, Wirth, Hauser, Köster and Hornef. This is an open-access article distributed under the terms of the Creative Commons Attribution License (CC BY). The use, distribution or reproduction in other forums is permitted, provided the original author(s) or licensor are credited and that the original publication in this journal is cited, in accordance with accepted academic practice. No use, distribution or reproduction is permitted which does not comply with these terms. 